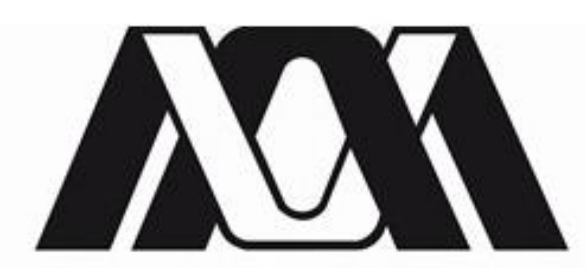

Casa abierta al tiempo

UNIVERSIDAD AUTÓNOMA METROPOLITANA UNIDAD IZTAPALAPA

\title{
ESTRUCTURA ECOLÓGICA FUNCIONAL DEL GREMIO DE MESODEPREDADORES EN EL MATORRAL XERÓFILO DE OTLALTEPEC PUEBLA
}

\author{
TESIS \\ Que para obtener el grado de \\ Maestra en Biología \\ PRESENTA
}

Biól. Alejandra Margarita López Ramos

Comité tutoral:

Director: Dr. Miguel Ángel Armella Villalpando

Asesores: M. en C. María de la Asunción Soto Álvarez

M. en C. Gerardo López Ortega

Ciudad de México

Junio 2018 
La Maestría en Biología de la

Universidad Autónoma Metropolitana

pertenece al Padrón de

Postgrados de Calidad del CONACyT. 


\section{El jurado designado por la \\ División de Ciencias Biológicas y de la Salud de la Unidad Iztapalapa aprobó la tesis que presentó \\ Alejandra Margarita López Ramos}

El dia 01 de junio del año de 2018.

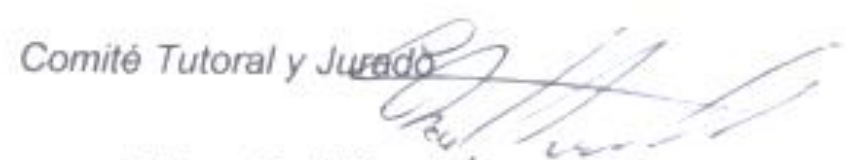

Tutor: Dr. Miguel Ángel Armella Villalpando

Asesor: M. en C. Gerardo López Ortega

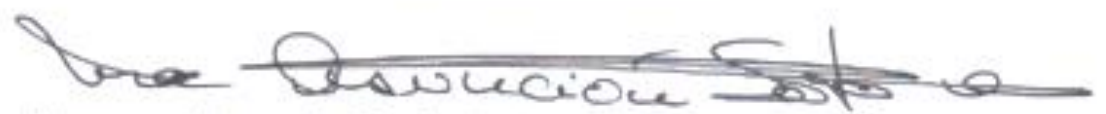

Asesor: M. en C. María de la Asunción Soto Álvarez

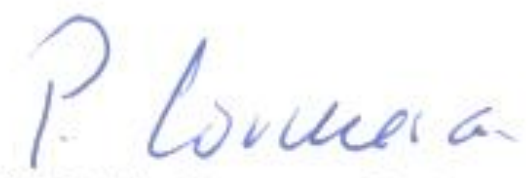

Sinodal: Dr. Pablo Corcuera Martinez del Río

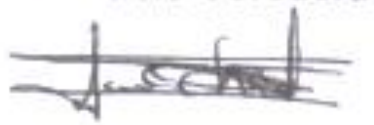

Sinodal: Dr. José Cuauhtémoc Chávez Tovar 
BSTRUCTURA ECOLOGICA FUNCIONAL DEL GREMIO DE MESODEPREDADORES EN EI

MATORRAL XEROEITO DE OTLALTEPEC, PUEBLA.

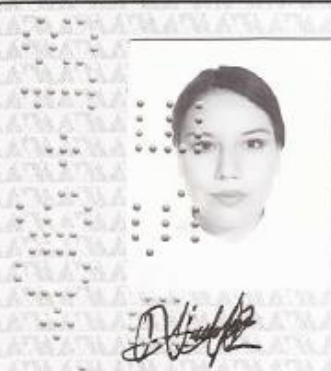

ALE.JANDRA MARGARITA LOPEZ RAMOS

$$
\because \text { ALUMNA }
$$

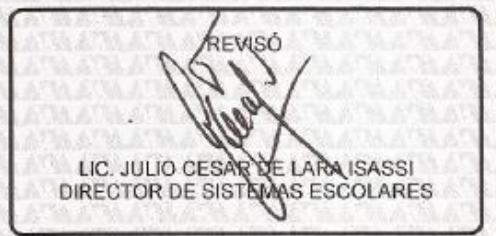

Acto continuo, el presidente del jurado comunicó a là interesada el resultado de la evaluación $y$, en caso aprobatorio, le fue tomada la protesta.
En la Cludad de México, se presentaron a las 12:00 horas del dia 1 del mes de junio del año 2018 en la Unidad Iztapalapa de la Universidad Butonoma Metropolitana, los suscritos miembros del jurado:

DR. PABLO CORCUERA MARTINEZ DEL RIO

M. EN C. GERARDO LOPEZ ORTEGA

DR. JOSE CUAUHTEMOC CHAVEZ TOVAR

M. EN C. MARIA DE LA ASUNCION SOTO ALVAREZ

Bajo la Presidencia del primero y con carácter de Secretario el ultimo, se reunieron para proceder al Examen de Grado cuya denominación aparece al margen, para 1 obtención del grado de:

MAESTRA EN BIOLOGIA

DE: ALEJANDRA MARGARITA LOPEZ RAMOS

y de acuerdo con el articulo 78 fracción III del Reglamento de Estudios Superiores de la Universidad Autonoma Metropolitana, los miembros del jurado resolvieron:

\section{Aprobon}

DIRECTORA DE LA DIVISJÓN DE CBS

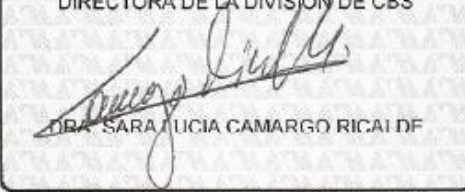

$$
1 \text { Colculel }
$$

DR. PABLO CORCUERA MARTINEZ DEL RIO

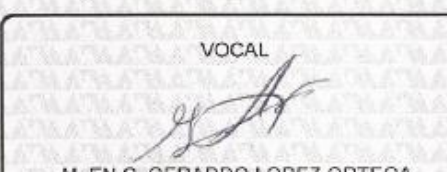

M. EN C. GERARDO LOPEZ ORTEGA
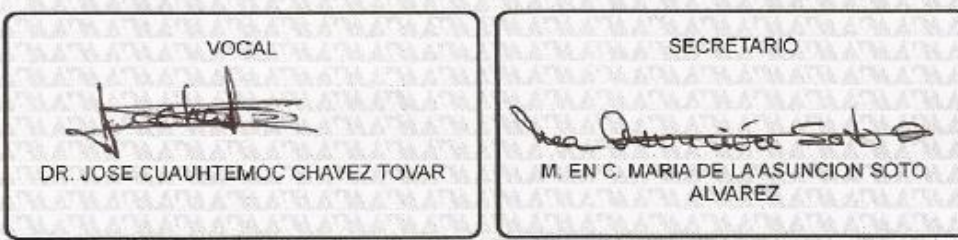
A mi hermoso País, porque en cada uno de sus rinconcitos encuentro magia.

A mis padres por todo su amor y apoyo incondicional. 


\section{Agradecimientos}

Al pueblo mexicano, por el apoyo económico para la realización de esta tesis por medio de la beca de posgrado que otorga CONACyT.

A la Universidad Autónoma Metropolitana, por ser mi segunda casa, siendo el pilar de mi formación como bióloga y por darme tanto.

A los habitantes de Otlaltepec, por permitirnos realizar este trabajo. En especial a la familia Amador por abrirnos las puertas de su casa.

Al Dr. Miguel Ángel Armella Villalpando, quien encabezó mi comité tutoral. Gracias por todo su apoyo, consejos, dedicación y la confianza depositada. Por ser un buen padre académico.

A la M. en C. María de la Asunción Soto Álvarez, por ser una excelente profesora que inspira a quienes fuimos sus alumnos; por su cordialidad y por otorgar esa apertura a los estudiantes para la realización de proyectos de investigación.

Al M. en C. Gerardo López Ortega, por su entusiasmo, paciencia y gran sentido del humor. Por ver cosas más allá de lo aparente y cuyos aportes a esta tesis fueron de suma importancia.

Al Dr. Pablo Corcuera Martínez del Río, por sus puntuales correcciones y por promover la convivencia dentro del Laboratorio de Ecología Animal.

Al Dr. Cuauhtémoc Chávez Tovar, por aceptar ser parte del jurado de la tesis y sugerir cambios y correcciones que permitieron mejorar la versión final de esta tesis. 
A la Dra. María de Lourdes Yáñez López, por su confianza, su calidez humana y por siempre acompañarnos en los viajes con una sonrisa.

Al Dr. Noé González Ruíz, al M. en C. Matías Martínez Coronel y al biólogo Juan Luis Patiño, por sus asesorías, apoyo y orientación en la identificación de mamíferos y reptiles, por haber sido tan accesibles. Gracias.

A los biólogos Adrián González, Desire Mera, y a la bioquímica Viridiana Millán, por su apoyo en las salidas de campo.

A la M. en B. Yess Márquez por su amistad, compañerismo y por su ayuda en la identificación de insectos.

A mis compañeros y amigos del Laboratorio de Ecología Animal: Norma, Carmen, Marco y Omar. Gracias por su apoyo, por esas pláticas y momentos tan divertidos; y por dejarme ser. Los quiero.

A mis amigas de la UAM-I: Nancy, Peny, Odemaris y Sandra, por ser tan bellas personas, por todo su apoyo, cariño, consejos y pláticas. Su amistad es invaluable.

A mis amigas Silvia, Yoseline, Brenda, Guadalupe, Yoloxóchitl y Montse por todo su amor, apoyo, consejos, y momentos divertidos. Ustedes aportan mucha felicidad a mi vida. Las amo. 
ÍNDICE

RESUMEN

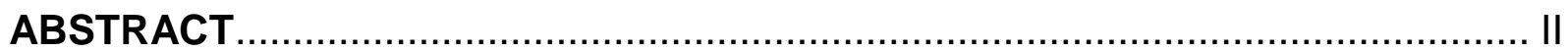

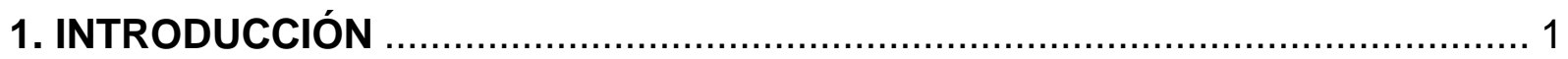

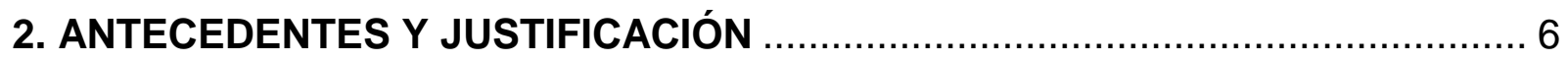

3. PLANTEAMIENTO DE LA INVESTIGACIÓN................................................. 11

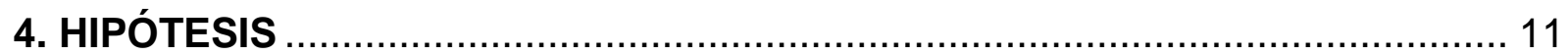

5. OBJETIVOS

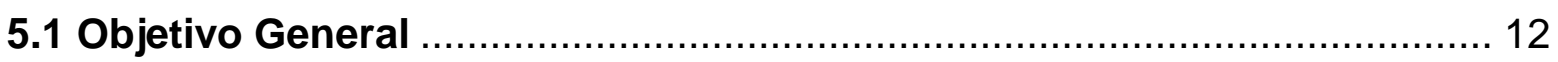

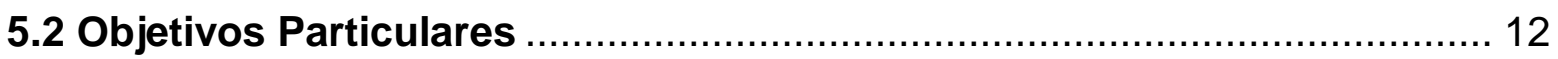

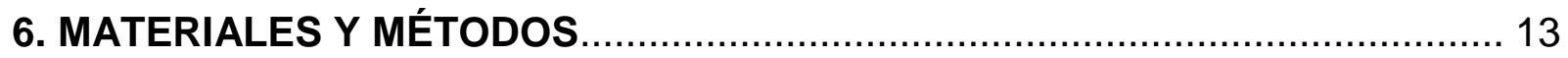

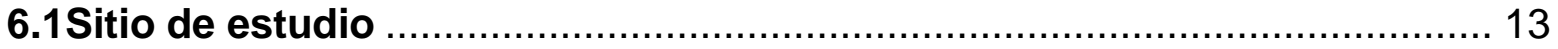

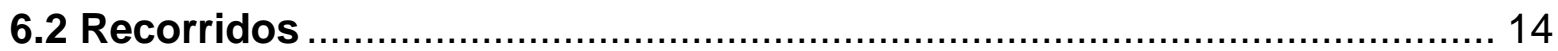

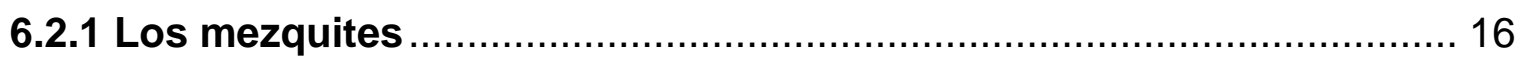

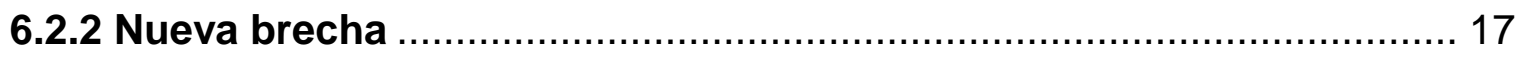

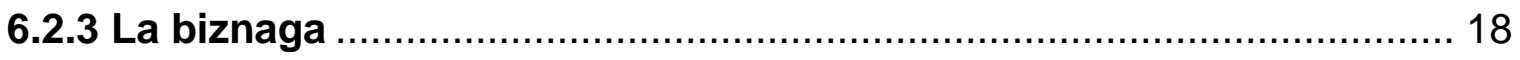

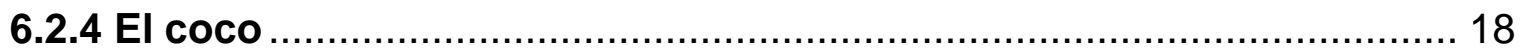

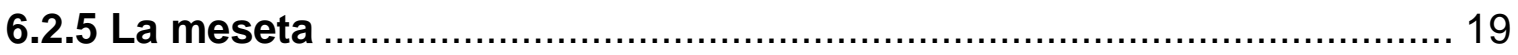

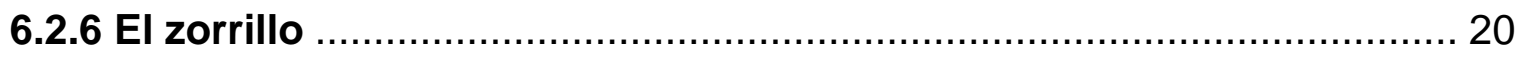

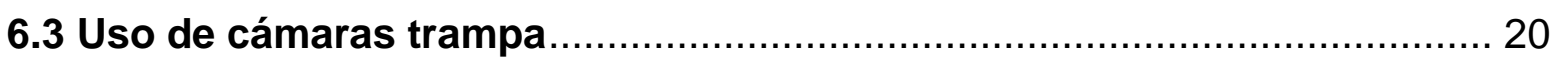

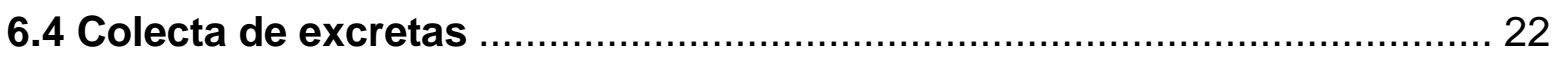

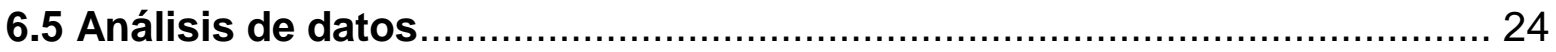

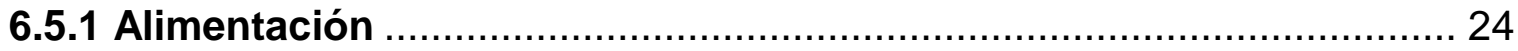

6.5.1.1 Determinación de los componentes de la dieta ............................. 25

6.5.1.2 Amplitud de nicho alimenticio .................................................... 26

6.5.1.3 Sobreposición de nicho alimenticio............................................ 26

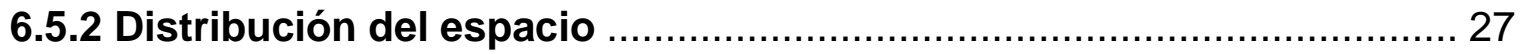

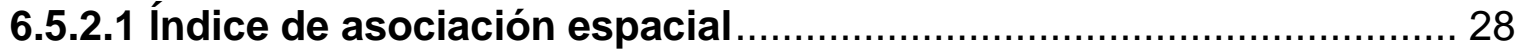

6.5.2.2 Utilización temporal del espacio ................................................... 29

7. RESULTADOS

7.1 Alimentación de los mesodepredadores .............................................. 31 
7.1.1 Alimentación de Canis latrans....................................................... 31

7.1. 2 Alimentación de Urocyon cinereoargenteus .................................... 34

7.1.3 Alimentación de Bassariscus astutus .......................................... 37

7.1.4 Alimentación de Lynx rufus........................................................ 40

7.1.5 Amplitud de nicho de alimentación.................................................. 42

7.2 Sobreposición de nicho de alimentación ................................................ 44

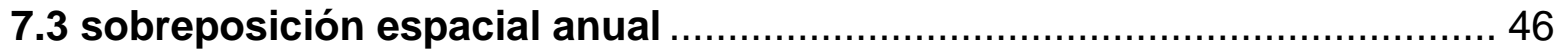

7.3.1 Sobreposición espacial en las dos temporadas ............................... 47

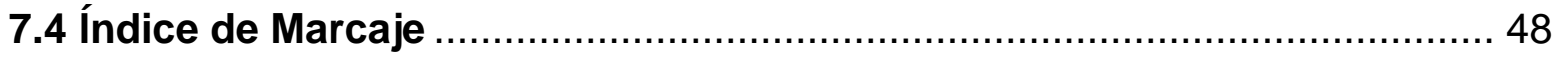

7.4.1 Marcaje de los mesodepredadores en temporada de secas............... 48

7.4.2 Marcaje de los mesodepredadores en temporada de lluvias.............. 49

7.5 Distribución temporal de los mesodepredadores.................................. 50

7.5.1 Actividad de Canis latrans ........................................................ 52

7.5.2 Actividad de Urocyon cinereoargenteus ......................................... 53

7.5.3 Actividad de Bassariscus astutus ................................................. 54

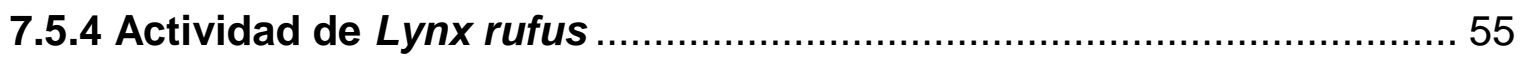

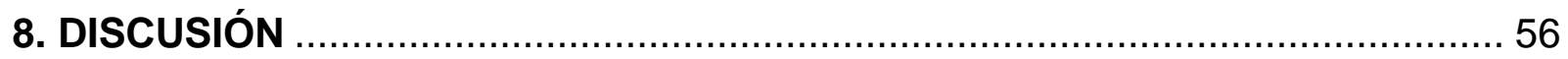

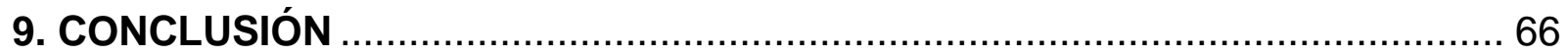

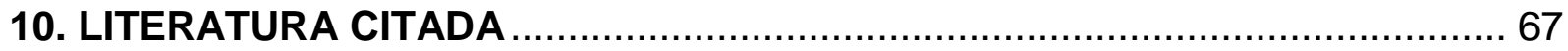




\section{RESUMEN}

Este trabajo se realizó con el objetivo de entender cómo es la estructura ecológica funcional de un gremio de mesodepredadores en términos del uso de los recursos alimenticio, espacial y temporal en el matorral xerófilo de Santo Tomás Otlaltepec, Puebla. En esta zona se establecieron 6 recorridos en los que periódicamente se realizaron colectas de excretas para determinar los siguientes puntos: los componentes de la dieta de cada especie, el grado de sobreposición espacial y su dominancia mediante el marcaje. Asimismo se colocaron cámaras trampa para conocer los patrones de actividad de las especies. Los resultados permitieron determinar que, entre los mesodepredadores estudiados, Canis latrans fue la especie dominante dentro del gremio, pues en comparación con Lynx rufus, Urocyon cinereoargenteus y Bassariscus astutus, la especie tuvo la mayor amplitud de nicho alimenticio, el mayor número de registros por cámaras trampa y fue localizado en todos los transectos. También fue la especie que usó en mayor medida sus excretas como indicativos de su presencia, seguido en orden jerarquico por $L$. rufus, $U$. cinereoargenteus y $B$. astutus. La estructura ecológica funcional del gremio está dada en función del reparto y la disponibilidad de recursos presentes en la zona a lo largo del año. La diferencia en el uso de los recursos alimenticios, del espacio y de tiempo fue evidente entre las especies, esto puede interpretarse como un efecto de la competencia interespecífica y el desplazamiento de nicho. Los patrones alimenticios encontrados muestran que la competencia interespecífica es menor que la intraespecífica, permitiendo la coexistencia entre las especies. 


\begin{abstract}
The goal of this study was to understand how the functional ecological structure of a guild of mesopredators works in terms of the use of food, spatial and temporal resources in the xerophilous scrub of Santo Tomás Otlaltepec, Puebla. In this area, were established 6 transects in which scats from mid size predators were collected every 45 days to determine: the components of the diet of each species, the degree of spatial overlap and its dominance through marking. Also trap-cameras were placed to gather information about the activity patterns of the species. The main results show that Canis latrans is the dominant species within the guild, because in comparison with Lynx rufus, Urocyon cinereoargenteus and Bassariscus astutus, the species had the largest niche breadth, the highest number of photographs and was present in all the transects. In addition, it was the species that used its scats more frequently as indicative of its presence, followed in hierarchical order by $L$. rufus, $U$. cinereoargenteus and $B$. astutus. The ecological structure of the guild is based on the distribution and availability of resources present in the area throughout the year. There was an evident differentiation in the use of food resources, space and time between species. This can be interpreted as an effect of interspecific competition and niche displacement. Food patterns showed that interspecific competition was smaller than intraspecific competition, allowing coexistence between the species.
\end{abstract}




\section{INTRODUCCIÓN}

Uno de los principales intereses en la ecología de comunidades ha sido comprender cómo se estructuran y funcionan los ecosistemas. Desde el punto de vista de su estructura los componentes del ecosistema se relacionan entre sí mediante el flujo de materia y energía, por lo que los organismos han sido agrupados en diferentes niveles tróficos (Begon et al., 1997).

La estructura y el funcionamiento dentro de una comunidad puede ser descrita desde un nivel jerárquico a partir de la interacción entre las especies presentes, por medio de clasificaciones no filogenéticas de organismos. Para conocer mejor la organización de las comunidades animales, podemos dividir sus niveles tróficos en "gremios". En 1967 Root definió gremio como "un grupo de especies que explotan por igual los mismos recursos ambientales o bien las especies que se solapan significativamente en los requerimientos de su nicho" (Begon et al., 1997).

Hairston et al., en 1960 propusieron un modelo conceptual simple para explicar las interacciones en un nivel trófico de las comunidades terrestres. Estos autores sugirieron que las comunidades consisten de cuatro grupos de organismos (carnívoros, herbívoros, autótrofos, detritívoros) que con sus interacciones tróficas explican qué las plantas dominan la tierra debido a que los carnívoros controlan la abundancia de herbívoros y de esta forma la vegetación es liberada del control que los herbívoros ejercen sobre ella y sugieren que la biomasa orgánica no es acumulable. 
También explican que los detritívoros al tener recursos limitados, evitan de forma global la acumulación de materia orgánica contribuyendo a los ciclos biogeoquímicos. Por lo tanto, las poblaciones de carnívoros y detritívoros son reguladas por la competencia, que los herbívoros eran controlados por depredación directa y los carnívoros regulan de forma indirecta la abundancia de la vegetación.

La perspectiva general en este modelo, es que las comunidades están reguladas por procesos cuyo efecto fluye de forma descendente en la cadena alimentaria. Más tarde este concepto fue denominado control "de arriba abajo" o "top-down" (Hunter y Price, 1992).

Ritchie y Jonhson (2009) definen como depredadores punta a aquellas especies que ocupan la posición trófica superior dentro de una comunidad. Estas especies a menudo son cazadores especializados de talla grande. Sin embargo, los grandes mamíferos depredadores están desapareciendo de su hábitat debido a varios factores como la caza furtiva, tanto de ellos como de otras especies que les sirven de alimento, por lo que muchos carnívoros no encuentran una base de presas adecuada para sobrevivir. Además, debido a que los grandes depredadores requieren amplios territorios para solventar sus requerimientos energéticos, la pérdida y fragmentación del hábitat natural como consecuencia del avance de la frontera agropecuaria y otras actividades humanas, los afectan más que a otros mamíferos de tamaño equivalente. De igual manera, en áreas fragmentadas la probabilidad de conflictos directos entre estos animales y los humanos aumenta (en parte por el posible ataque a los animales domésticos) provocando así un aumento en los niveles de persecución (Bitteti, 2008; Prugh et al., 2009). 
Naranjo et al. (2010) mencionan que la "defaunación es selectiva" ya que las especies más afectadas se encuentran en la punta de las cadenas tróficas. Esta defaunación produce una reacción en cadena, al desaparecer los grandes depredadores, se da un aumento poblacional de sus presas.

Estudios recientes han destacado la importancia de los depredadores punta en la supresión de las poblaciones de depredadores más pequeños (mesodepredadores) y con ello, moderando el impacto de depredación de pequeñas especies presa (Crooks y Soulé, 1999; Johnson et al., 2006; Berger et al., 2008).

Cuando las poblaciones de los depredadores punta se reducen o desaparecen, las poblaciones de mesodepredadores (o de talla media) antes suprimidas, incrementan en un fenómeno conocido como la "liberación del mesodepredador" (Soulé et al., 1988; Courchamp et al., 1999; Crooks y Soulé, 1999). Estos mamíferos suelen ser más adaptables a cambios ambientales, al tener intervalos de alimento más amplios que los originales depredadores punta.

La fragmentación de un área puede añadir recursos disponibles para los mesodepredadores como, basura, cultivos, alimento para mascotas y plagas de cultivos que a menudo acompañan al desarrollo antropogénico (Crooks y Soulé, 1999; Wangchuck, 2004).

Algunos autores han definido como mesodepredadores a mamíferos depredadores de tamaño medio con cierto rango de peso (por ejemplo, de 1 a 15 kilogramos, Buskirk, 1999; Gehrt y Clark, 2003) pero estos rangos de peso son arbitrarios y sin relación con los patrones ecológicos centrales de la "liberación del mesodepredador". Prugh et al., (2009) mencionan que "Si el término basa sus raíces en la teoría ecológica, un 
mesodepredador debería definirse como cualquier depredador de mediano rango en una red alimentaria, independientemente de su tamaño o taxonomía". Por lo tanto, un mesodepredador puede ser depredador punta en un ecosistema y puede no serlo en otro, además un ecosistema puede tener varios mesodepredadores (Roemer et al., 2009). Esto depende entre otros factores a la parte histórica, y a que probablemente muchos de los ecosistemas en donde un mesodepredador es punta se debe a la desaparición de los depredadores tope. Por ello, la definición de depredador punta y mesodepredador son relativas y dependen de las interacciones con otros depredadores. Por ejemplo, el coyote (Canis latrans Say, 1823) puede ser considerado un depredador punta (Crooks y Soulé, 1999). Sin embargo, al co-existir con otros depredadores punta como el puma o el lobo, el coyote se puede considerar como un mesodepredador (Berger et al., 2008).

Los mesodepredadores al explotar la misma clase de recursos de forma similar han sido agrupados dentro de un mismo gremio. Estas especies (que no necesariamente están emparentadas) coexisten dentro de una comunidad y al tener necesidades parecidas pueden entrar en competencia, definida como "una interacción entre individuos, provocada por la necesidad común de un recurso limitado, y que conduce a la reducción de la supervivencia, el crecimiento y/o la reproducción de al menos algunos de los individuos competidores implicados" (Begon et al., 1997; Smith y Smith, 2007).

Las observaciones para las especies que interaccionan sugieren que su coexistencia se debe a la repartición de los recursos disponibles reduciendo la competencia directa. Usan diferentes tipos y tamaños de alimento, se alimentan en diferentes momentos o 
se aprovisionan en diferentes áreas como resultado de la competencia interespecífica. Cada especie explota una parte de los recursos no disponibles para otros, lo cual origina diferencias entre especies que conviven que no se esperaría puramente por casualidad (Smith y Smith, 2007). "El reparto de recursos es el resultado de adaptaciones fisiológicas, morfológicas o conductuales específicas que permite a los individuos tener acceso a los recursos esenciales y por lo tanto influyen sobre su adaptación al medio" (Smith, 1955, citado en Smith y Smith, 2007).

Estas interacciones han llevado al concepto de nicho ecológico definido por Hutchinson (1957) como el espacio multidimensional o hipervolumen que es igual al espacio físico que ocupa el organismo, su papel funcional dentro de la comunidad, y las condiciones de existencia. Si cada condición, recurso o acción, son considerados como una dimensión, el proceso puede continuar $n$ veces y el verdadero nicho ecológico de una especie puede ser imaginado como un hipervolumen de $n$ dimensiones (Begon, 1997). Hutchinson también, hizo una distinción entre el nicho fundamental definido como el rango total de condiciones bajo las cuales una especie puede sobrevivir, crecer y reproducirse, en ausencia de competidores. $\mathrm{Y}$ el nicho efectivo que comprende la porción de nicho fundamental que una especie verdaderamente ocupa como resultado de las interacciones con otras especies.

De este modo, podemos hablar de los mamíferos carnívoros de "tamaño medio" que al ser tan parecidos en sus necesidades, tienden a utilizar recursos similares, provocando una sobreposición de nicho en cualquiera de sus dimensiones, y si el grado de utilización de los mismos recursos es muy alto, uno de ellos será desplazado, dándose así una diferenciación de nicho entre las especies que conforman al gremio. 
La concepción del nicho ecológico, ha permitido dar un enfoque cuantitativo, cuya base se encuentra en dos descriptores: la amplitud y sobreposción (Smith, 1982).

Si lo que se tiene es el resultado de procesos evolutivos y ecológicos, entonces para poder medir la interacción y competencia entre las diferentes especies pertenecientes al gremio de mesodepredadores, deben ser seleccionadas diferentes categorías o fracciones de nicho para con esto, poder estimar la forma en que las especies usan esas categorías y, saber si hay sobreposición o no y en qué medida.

\section{ANTECEDENTES Y JUSTIFICACIÓN}

Los mamíferos carnívoros de talla media o mesodepredadores son especies que presentan mayor flexibilidad adaptativa, por lo que son más abundantes que los grandes carnívoros. Pueden encontrarse en sitios poco perturbados, así como también en zonas muy cercanas a los asentamientos humanos, ser solitarios o altamente sociables y tener una dieta restringida (hipercarnívora) a una más omnívora. Normalmente concentran su actividad durante la noche, pero también pueden dedicar parte del amanecer y del crepúsculo a la búsqueda de refugio y alimento (Bekoff, 1977; Fritzell y Haroldson, 1982; Lariviére y Walton, 1997; Hwang y Lariviére, 2001; Castellanos, 2006; Kasper et al., 2009; Roemer et al., 2009; Gwinn et al., 2011). Estos hábitos hacen que sean difíciles de estudiar, por lo que es necesario recurrir a métodos indirectos para obtener información sobre estas especies. Hay pocos trabajos que abordan al grupo como tal, siendo relativamente más comunes aquellos trabajos autoecológicos para algunas de las especies. Uno de los trabajos que ha incluido a un 
conjunto de mesodepredadores es el de Guerrero et al., (2002) quienes analizaron la dieta, la amplitud y sobreposición de nicho alimenticio del coyote (Canis latrans), zorra gris (Urocyon cinereoargenteus Schreber, 1775), mapache (Procyon lotor) y jaguarundi (Herpailurus yagouaroundi) en un bosque tropical caducifolio de la costa sur del estado de Jalisco, por medio del análisis de excretas. En otro estudio, GarcíaChávez et al., (1994) determinaron la riqueza de especies de mamíferos carnívoros por medio de huellas y excretas en los alrededores de Zapotitlán de Salinas, Puebla. En éste se encontraron cuatro especies de mesodepredadores: coyote (Canis latrans) zorra gris (Urocyon cinereoargenteus), cacomixtle (Bassariscus astutus, Lichtenstein, 1830) y zorrillo rayado (Mephitis macroura, Lichtenstein 1832). Cervantes y Riveros (2012) en el matorral xerófilo de Cosoltepec, Oaxaca, registraron 32 especies de mamíferos medianos, entre los que se encuentran el coyote, lince, tlacuache, zorra gris, zorrillo cadeno y cacomixtle. Toríz (2014), reportó la presencia de varios mesodepredadores en Otlaltepec, Puebla, así como algunos aspectos ecológicos de éstos. Haciendo uso cámaras trampa, obtuvo en total 40 registros de mesodepredadores, correspondientes a cinco familias, nueve géneros y nueve especies.

La especie con mayor cantidad de registros fueron Bassariscus astutus (12), seguida de Canis latrans (10), Conepatus leuconotus (4), Urocyon cinereoargenteus (4) y finalmente Procyon lotor (3). Estos resultados permiten sugerir una presencia importante de mesodepredadores en la zona que se abarca en el presente estudio, sin embargo, no se estudiaron las interacciones ecológicas entre los mesodepredadores. 
Las excretas de la fauna silvestre, principalmente en el caso de los mamíferos, proporcionan de una gran cantidad de información ecológica como puede ser la presencia, abundancia relativa, distribución, incluso el estado de salud.

La colecta de excretas resulta ser una fuente de información no invasiva y de bajo costo para determinar la dieta de una especie y evaluar sus relaciones ecológicas. Por medio de las excretas también se pueden analizar los procesos de señalizaciones odoríferas y visuales que usan los animales. (Livingstone et al., 2005; Reynolds et al., 1991; Barja y List, 2006; Valdespino et al., 2007).

El alimento es una de las dimensiones de nicho más estudiadas, pues permite evaluar cómo se reparten los recursos alimenticios disponibles en una comunidad. Cuan específica o generalista es su dieta, y el grado de competencia entre los miembros del gremio en esta dimensión de nicho (Krebs, 1999; Guerrero et al., 2002).

Además del alimento, otro aspecto que se considera para evaluar el nicho de una especie es la utilización del espacio. El marcaje odorífero ha sido definido como las secreciones y excreciones que deja un animal sobre áreas u objetos (Wells y Bekoff, 1981). Entre los cánidos y otras especies puede servir como un mecanismo para el mantenimiento del territorio, de reconocimiento de sexo, como un indicador de la madurez sexual del organismo, así como un mecanismo de comunicación interna para orientar a miembros del grupo y disuadir animales que puedan entrar en territorios ocupados y para que las especies dominantes hagan valer su jerarquía dentro del territorio ante especies más pequeñas (Gese y Ruff, 1997).

El marcaje en los mamíferos no es aleatorio, Barja et al., (2008) en un estudio sobre el marcaje de Canis lupus signatus en vida libre, encontraron que existe una 
preferencia en cuanto a la selección del sustrato y de la apariencia física de las plantas seleccionadas para usar como marcaje. Para determinar si una excreta tiene función de marcaje o no, los mismos autores, tomaron en cuenta varios factores como su ubicación en un camino o sendero, si se encontraban a nivel del suelo o por arriba de éste, el tipo de sustrato y la cantidad. En un trabajo similar, Barja y List (2006), analizaron la selección de letrinas de marcaje de Bassariscus astutus, demostrando que la distribución espacial de las letrinas no era aleatoria, sino que se distribuían con base en el tipo de sustrato y las zonas que hacen más efectivo el marcaje fecal.

En los matorrales xerófilos los mesodepredadores tienen importancia ecológica ya que suelen controlar las poblaciones de roedores y en condiciones de sequía pueden tornarse incluso vegetarianos, volviéndose efectivos dispersores de semillas.

Los mesodepredadores al presentar un intervalo alimenticio amplio, pueden utilizar diferentes elementos para complementar su dieta, lo que puede reducir la competencia especialmente durante el periodo de escasez de alimento que coincide con la temporada de secas.

Por lo tanto, la forma en la que los mesodepredadores se reparten los recursos resulta particularmente relevante en el funcionamiento ecológico de estos ecosistemas (Villalobos et al., 2014). 
Desde el año 2010 el personal académico adscrito al Laboratorio de Ecología Animal de la UAM unidad Iztapalapa junto con alumnos de licenciatura y posgrado han estado desarrollando Proyectos de Investigación en el área adyacente a la comunidad de Santo Tomás Otlaltepec, Puebla, que comprende la parte noroccidental de la Reserva de la Biosfera de Tehuacán-Cuicatlán. En estos proyectos se ha podido determinar la presencia, horarios de actividad y la dominancia de las especies que conforman al gremio de mesodepredadores, así como algunos indicios de su estructura ecológica (presencia de mesodepredadores, comportamiento, dominancia; Toríz, 2014). En el presente estudio se consideran los resultados encontrados anteriormente en la zona, y se usan los conceptos de nicho ecológico y competencia para explicar la estructura ecológica funcional de este grupo de mamíferos.

El tipo de interacción entre las especies que integran al gremio de mesodepredadores será estimada mediante tres categorías: alimentación, uso del espacio y tiempo. 


\section{PLANTEAMIENTO DE LA INVESTIGACIÓN}

Preguntas de investigación

- ¿Qué tan parecido es el alimento, la distribución espacial y la actividad diurna entre las especies que conforman al gremio de mamíferos mesodepredadores en la región de Otlaltepec, Puebla?

- ¿Cuál es la amplitud de nicho de cada una de las especies de mesodepredadores en términos del uso de los recursos: alimentación, espacio y tiempo en la región de Otlaltepec, Puebla?

- ¿Cuál es el grado de sobreposición de nicho entre las poblaciones pertenecientes al gremio de mesodepredadores en términos del uso de los recursos: alimentación, espacio y tiempo en la región de Otlaltepec, Puebla?

\section{HIPÓTESIS}

Si la competencia por el uso de los recursos alimenticios y del espacio, regula las relaciones ecológicas entre los mesodepredadores del matorral xerófilo de Santo Tomás Otlaltepec, entonces deberá existir sobreposición en las medidas de las diferentes dimensiones de hábitat de estos mesodepredadores. 


\section{OBJETIVOS}

\subsection{Objetivo General}

Describir como es la estructura funcional del gremio de mesodepredadores en términos del uso de los recursos: alimentación, espacio y tiempo en el Matorral xerófilo de Otlaltepec, Puebla.

\subsection{Objetivos Particulares}

1. Establecer las horas de actividad de las especies del gremio de mesodepredadores.

2. Conocer las diferencias y semejanzas en la explotación de los recursos alimenticios, uso espacial y temporal de los mesodepredadores a lo largo de un ciclo anual.

3. Determinar la amplitud de nicho.

4. Establecer las matrices de sobreposición de nicho. 


\section{MATERIALES Y MÉTODOS}

\subsection{Sitio de estudio}

El trabajo se realizó en los terrenos ejidales pertenecientes a Santo Tomás Otlaltepec, Municipio de Atexcal, Estado de Puebla. El sitio se localiza en el área de influencia de la Reserva de la Biosfera de Tehuacán-Cuicatlán, cerca del límite noroccidental de la misma y se encuentra aproximadamente a $4 \mathrm{~km}$ de la frontera Norte de Oaxaca, en las coordenadas $18^{\circ} 17^{\prime} 52.22^{\prime \prime}$ latitud norte y $97^{\circ} 45^{\prime} 37.18^{\prime \prime}$ longitud oeste.

Los terrenos ejidales de Santo Tomás Otlaltepec, se encuentran en un ecosistema de matorral xerófilo rosetófilo donde se practica la siembra de temporal y el pastoreo de ganado vacuno, mular y caprino y está conformada por lomeríos que descienden con orientación este-oeste. La altitud promedio es 2220 m.s.n.m. El tipo de suelo predominante es el leptosol (Arriaga et al., 2000; INEGI, 2009). El tipo de clima es semiárido, templado BS1hw:, la temperatura media anual mayor de $18^{\circ} \mathrm{C}$, la temperatura $10 \%$ del mes más frío menor de $18^{\circ} \mathrm{C}$, la temperatura del mes más caliente mayor de $22{ }^{\circ} \mathrm{C}$; con lluvias en verano del $5 \%$ al $10.2 \%$ anual (Gráfica 1). 


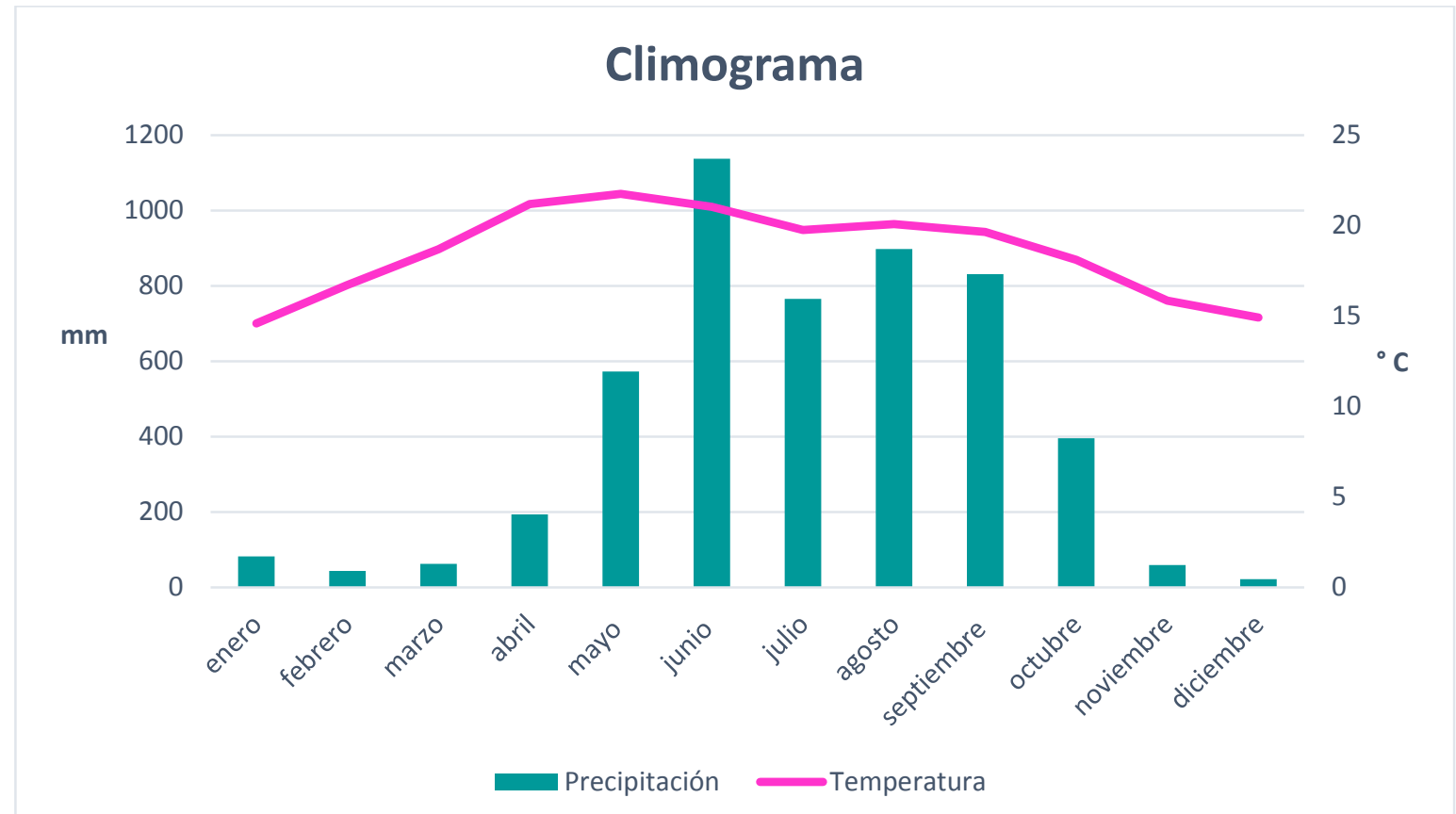

Gráfica 1. Climograma de precipitación y temperatura media mensual del año 2004 al 2014, de la estación meteorológica de Tehuacán estado de Puebla. La temporada de secas consideró los meses de enero, febrero, marzo, abril, noviembre y diciembre. La temporada de lluvias consideró los meses de mayo, junio, julio, agosto, septiembre y octubre.

Fuente: http://clicom-mex.cicese.mx/

\subsection{Recorridos}

El área de trabajo se encuentra al este-sur-este del pueblo, esta área fue dividida en seis sitios diferentes: "Los mezquites"; "Nueva brecha"; "La biznaga"; "El coco"; "La meseta" y "El zorrillo". Dentro de cada sitio se delimitó un recorrido de aproximadamente $1 \mathrm{~km}$ de longitud. Cada recorrido fue ubicado de manera sistemática sobre los caminos secundarios de la zona, partiendo de los sitios más cercanos al poblado hasta sitios en donde las actividades agrícolas y de pastoreo son nulas. Para garantizar la independencia de los transectos, estos fueron separados por una distancia de aproximadamente 500 metros y se ubicaron de manera paralela 
trazando tres al oriente y tres al poniente del río que dividía la barranca principal de la zona (ver fig. 1).

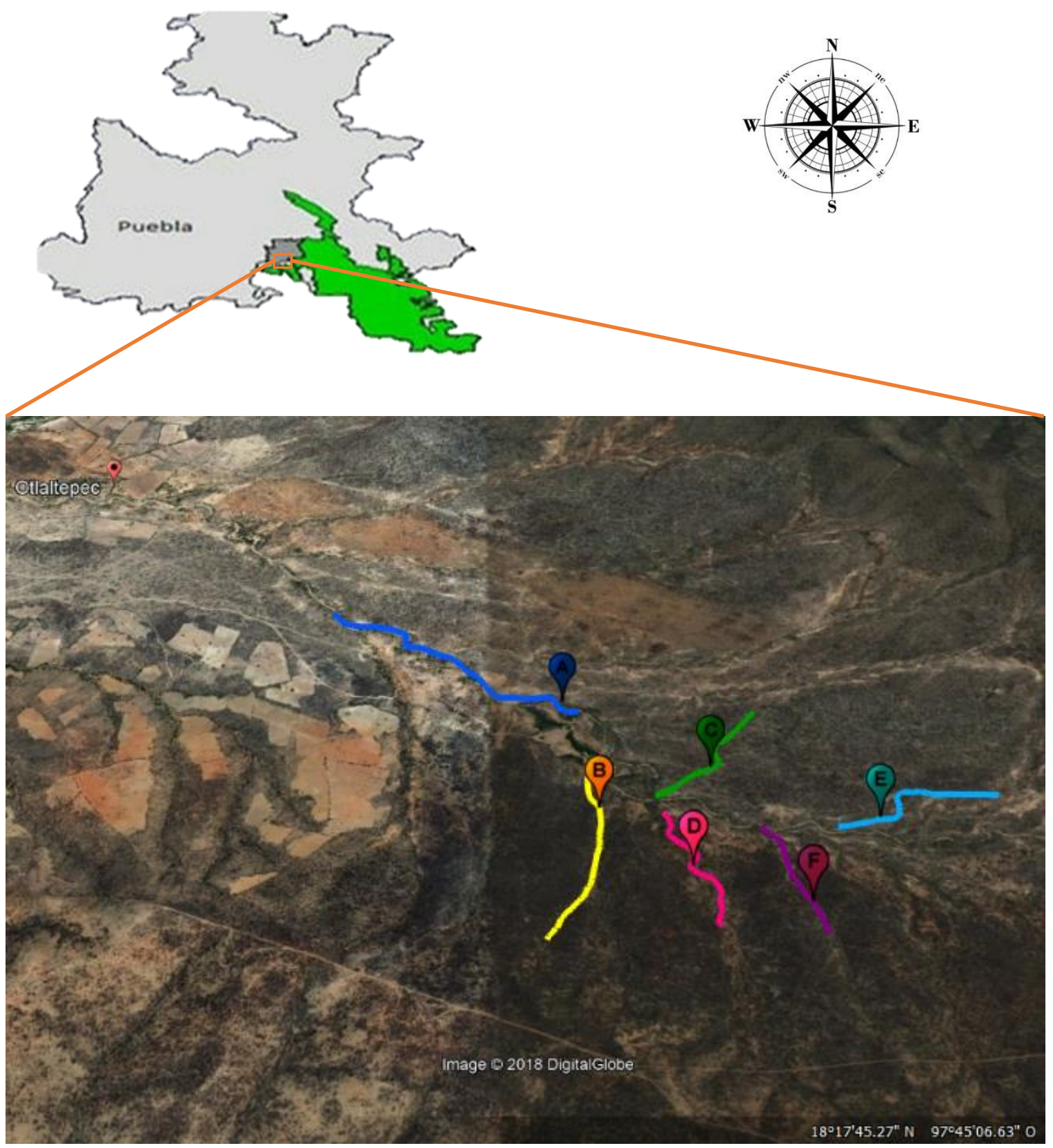

Figura 1. Mapa del estado de Puebla y localización de los transectos en Otlaltepec. En verde se ilustra la Reserva de la Biosfera Tehuacán-Cuicatlán. En un recuadro amarillo la localización del poblado. Con letras se señalan los recorridos de colecta en la zona de estudio: A) Los mezquites; B) Nueva brecha; C) La biznaga; D) El coco; E) La meseta y F) El zorrillo. (Google Earth, 2018). 
En general el tipo de vegetación en el área de estudio se enmarca como un matorral espinoso, deciduo con algunos elementos crasicaules y rosetófilos (clasificación basada en Rzedowski ,1988). Los recorridos fueron establecidos para obtener una muestra diversa entre ellos y no para determinar las diferencias entre las asociaciones vegetales presentes, ya que estas suelen presentarse en forma de parches con extensiones limitadas (de unas pocas decenas de metros cuadrados). Asociaciones vegetales que se repiten a lo largo y cerca de los recorridos son, por ejemplo, zonas donde abundan cactáceas como Neobuxbaumia mezcalaensis, plantas del género Yucca, matorrales intransitables (que pueden estar dominados por leguminosas como Mimosa lacerata, Mimosa polyantha o bien por Senna polyantha), arbustos espinosos como Castela erecta ssp. texana, Fouquieria splendens. Izotales, y cerca de las zonas húmedas o con fuentes de agua, aparecen árboles como los Prosopis.

\subsubsection{Los mezquites}

Este sitio es el más cercano al poblado. Se encuentra en las coordendas geográficas $18^{\circ} 17^{\prime} 18.4^{\prime \prime} \mathrm{N} ; 97^{\circ} 45^{\prime} 03.9^{\prime \prime} \mathrm{O}$ (Figura 1.1). Tiene un aporte constante de agua a lo largo del año. La altura promedio de la vegetación es de 3 a 4 m. Dos elementos dominan el paisaje, los Prosopis y Neobuxbaumia mezcalaensis cuyo periodo de floración se presenta desde el mes de marzo hasta mayo (Arias et al., 2000). 

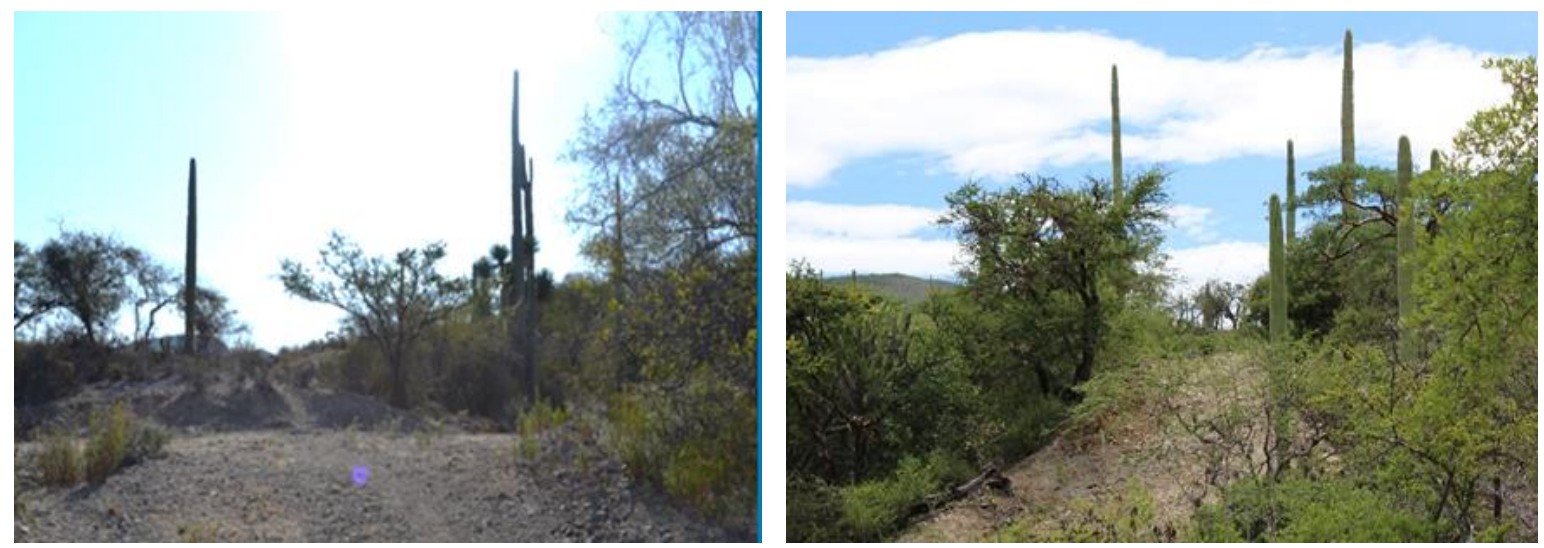

Figura 1.1 Recorrido "Los mezquites" temporada de secas y de lluvias

\subsubsection{Nueva brecha}

Sitio paralelo a "Los mezquites". Se encuentra en las coordenadas geográficas N 18 $17^{\prime} 03.0^{\prime \prime} \mathrm{O} 97^{\circ} 45^{\prime} 00.7^{\prime \prime}$ (Figura 1.2). La altura promedio de la vegetación es de $1.80 \mathrm{~m}$. Los arbustos espinosos que dominan el paisaje son Castela erecta ssp. texana y Fouquieria splendens; cuyo periodo de floración es entre los meses de julio y febrero. También se encuentran Neobuxbaumia mezcalaensis de manera aislada (Arias et al., 2000) y algunos árboles emergentes principalmente de leguminosas como Conzattia multiflora y Mimosa polyantha.

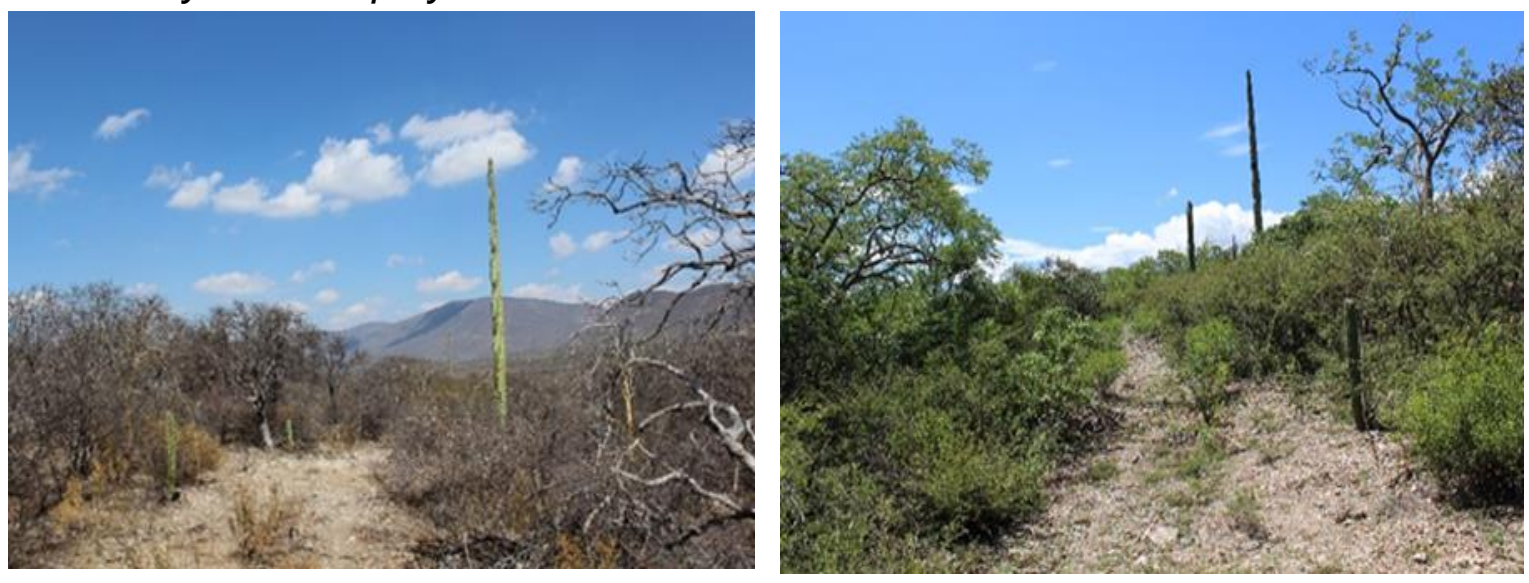

Figura 1.2 Recorrido "Nueva Brecha" temporada de secas y de lluvias. 


\subsubsection{La biznaga}

Sitio intermedio, ubicado en las coordenadas: N $18^{\circ} 17^{\prime} 07.1^{\prime \prime} \mathrm{O} 97^{\circ} 44^{\prime} 48.0^{\prime \prime}$ (Figura 1.3). La altura promedio de la vegetación es de $15 \mathrm{~m}$. Dominan las cactáceas columnares como Echinocactus platyacanthus y Neobuxbaumia mezcalensis. También hay presencia Yucca filifera que florece durante los meses de marzo y abril y arbustos espinosos como Castela erecta ssp. texana. (Arias et al., 2000).
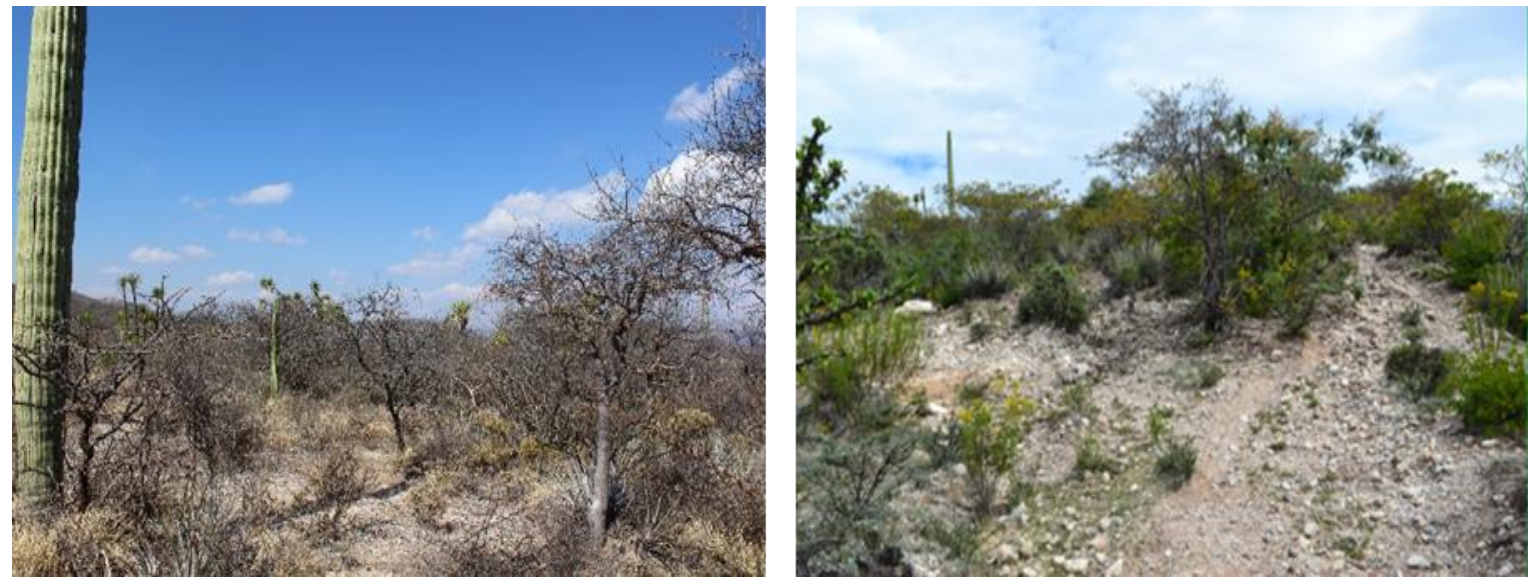

Figura 1.3 Recorrido "La biznaga" temporada de secas y de lluvias.

\subsubsection{El coco}

Este sitio es paralelo a "La biznaga" y se encuentra en las coordenadas: $\mathrm{N} 18^{\circ} 16^{\prime}$ 57.1”; O 97 4442.3". (Figura 1.4). La altura promedio de la vegetación es de 2 m. Es una zona parcialmente sombreada en donde dominan los arbustos espinosos como Castela tortuosa, esta especie florece casi todo el año, también hay presencia de Escontria chiotilla, que presenta floración dos veces al año: de marzo a mayo y de julio a agosto y Stenocereus pruinosus, cuyo periodo de floración es durante los meses de abril a agosto (Arias et al., 2000). 

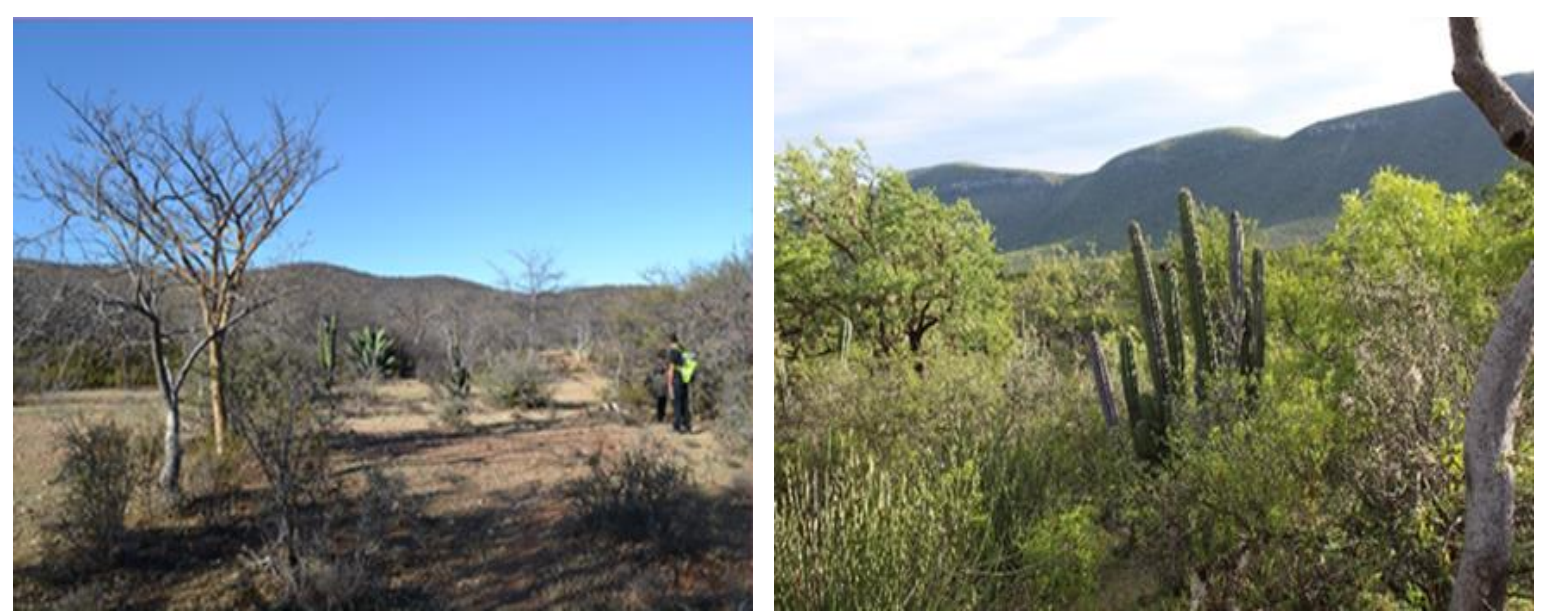

Figura 1.4 Recorrido "El coco" temporada de secas y de lluvias.

\subsubsection{La meseta}

Es el sitio más alejado al poblado, con coordenadas geográficas N 18²16'59.5”; O $97^{\circ}$ 44' 35.9". La altura promedio de la vegetación es $<1.50 \mathrm{~m}$, también hay zonas cercanas con vegetación de $2 \mathrm{~m}$ de altura, en donde dominan Yucca filifera y Dasylirion acrotrichum, cuyo periodo de floración es entre los meses de marzo y junio. También hay presencia de Agave kerchovei y Hechtia podantha como elementos aislados (Arias et al., 2000).
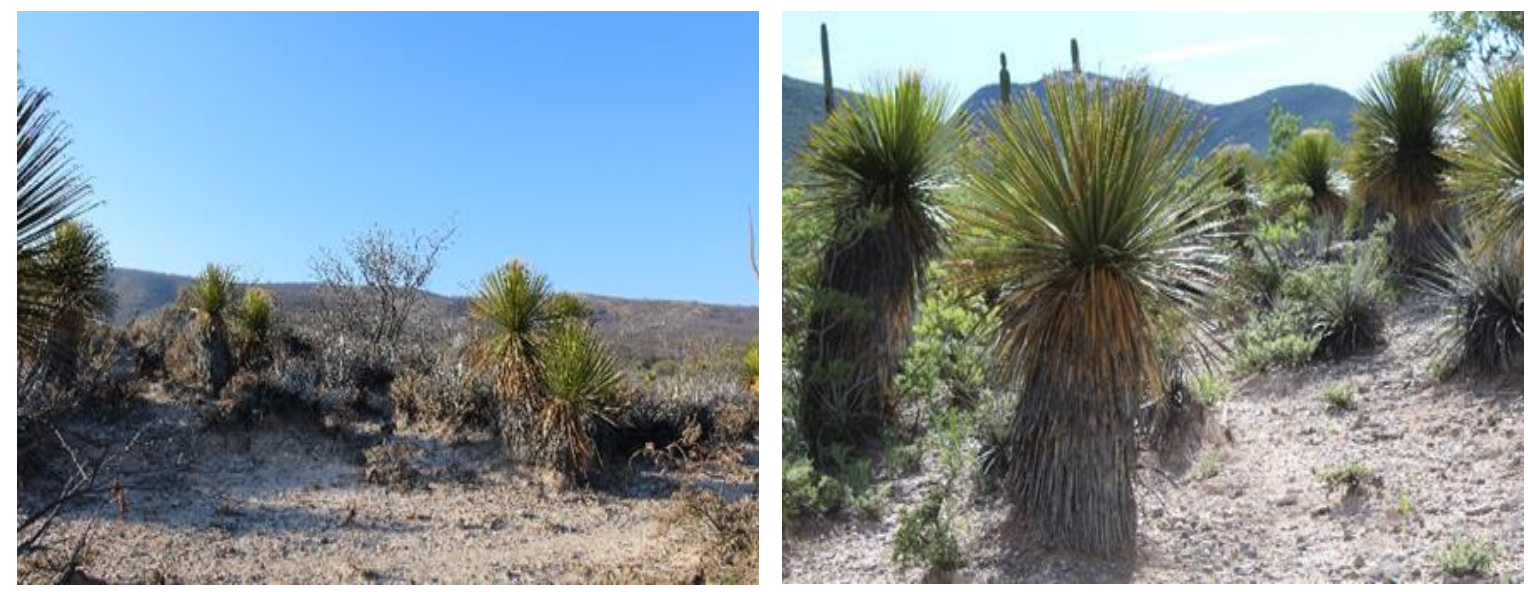

Figura 1.5 Recorrido "la meseta" temporada de secas y de lluvias. 


\subsubsection{El zorrillo}

Es un sitio paralelo a "La meseta" que se encuentra en las coordenadas geográficas: N 18 16’58.8” O $97^{\circ} 44^{\prime} 37.8^{\prime \prime}$ (Figura 1.6). La altura promedio de la vegetación es de $1.50 \mathrm{~m}$. En el paisaje dominan los arbustos espinosos caducifolios como Cascabela thevetia y Castela tortuosa. Como elementos aislados se encuentran presentes Myrtillocactus geometrizans, Yucca filifera Hechtia podantha. Plantas del género Bursera al igual que jatropha.
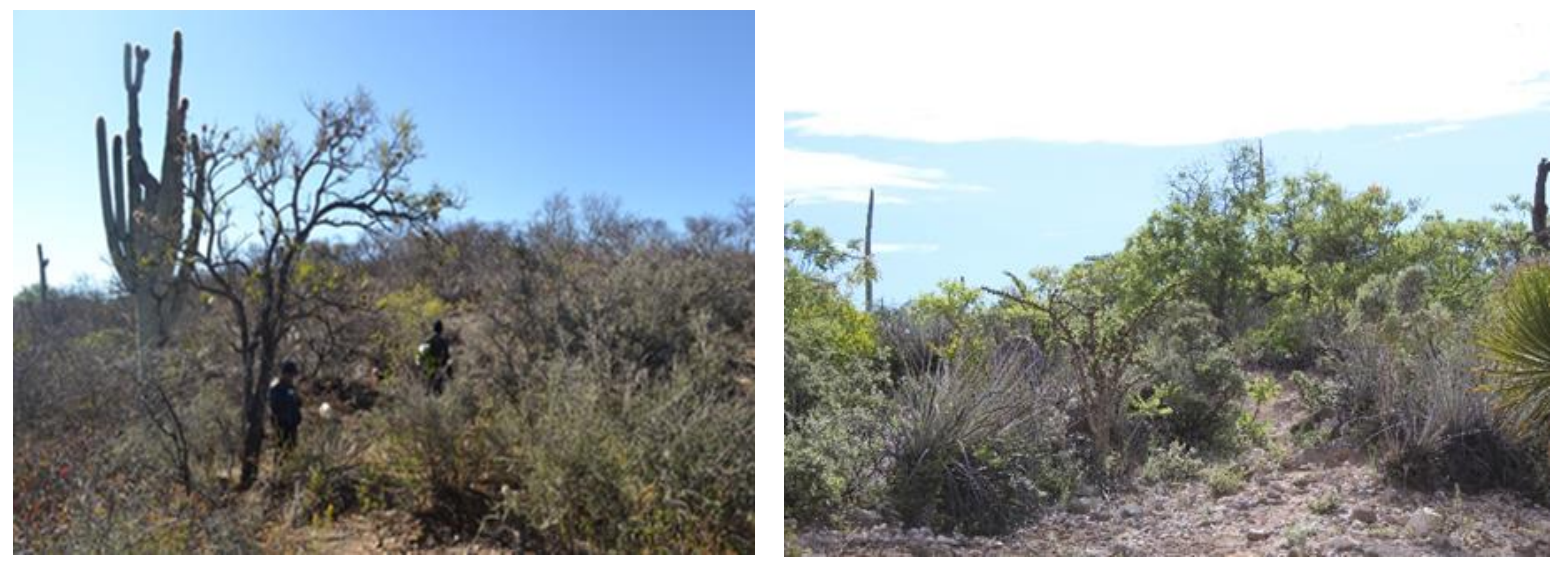

Figura 1.6 Recorrido "El zorrillo" temporada de secas y de lluvias.

\subsection{Uso de cámaras trampa}

Para determinar la presencia, abundancia relativa y los horarios de actividad de las diferentes especies que conforman al gremio en cuestión, se colocaron cinco cámaras trampa en las cabeceras o centros de los sitios establecidos (Cuadro 1). Estas cámaras permanecieron activas desde su colocación en diciembre del 2015, hasta enero del 2017 cuando fueron retiradas. 


\begin{tabular}{|l|l|l|}
\multicolumn{1}{|c}{ Sitio } & \multicolumn{1}{c|}{ Modelo } & \multicolumn{1}{c|}{$\begin{array}{c}\text { Colocación } \\
\text { de la cámara }\end{array}$} \\
\hline Nuevas brecha & --------------------- & $\mathrm{No}$ \\
\hline Los mezquites & Bushnell 119734C & $\mathrm{Si}$ \\
\hline La biznaga & Tasco 119255CW & $\mathrm{Si}$ \\
\hline El coco & Tasco 119255CW & $\mathrm{Si}$ \\
\hline La meseta & Wildview TGLX81R & $\mathrm{Si}$ \\
\hline El zorrillo & Wildview TGLX81R & $\mathrm{Si}$ \\
\hline
\end{tabular}

Tabla 1. Sitios de instalación de cámaras trampa.

La instalación se realizó tras una prospección de la zona de estudio, identificando sitios potenciales de paso de fauna silvestre (sitios clave). Las cámaras se situaron a $50 \mathrm{~cm}$ del suelo, sobre el tronco de un árbol y fueron amarradas con alambre, dentro de un soporte de hierro hecho a la medida. A partir de su colocación se revisaron cada 15 días y cada 45 días se cambiaron las baterías de cada una.

Las cámaras presentan sensores automáticos de movimiento y estuvieron activas las 24 horas del día. Se configuraron para tomar tres fotografías por segundo con intervalos de 1 minuto cada vez que se detectó movimiento. Se consideró como un solo registro todas aquellas fotografías tomadas a una especie dentro de un tiempo de 24 horas. En caso de que en subsecuentes fotografías se pudieran distinguir a diferentes individuos, entonces cada uno de estos fue considerado como un registro independiente (Hernández et al. 2015).

El esfuerzo de colecta se calculó como el número total de trampas colocadas por el total de días muestreados y el éxito de captura se tomó como el número total de registros / esfuerzo de colecta * 100 . 


\subsection{Colecta de excretas}

Previo al inicio del muestreo, cada uno de los transectos se revisó para retirar las excretas acumuladas hasta antes del presente estudio.

Los transectos se revisaron cada 45 días. Durante los recorridos se colectaron las excretas y su determinación se realizó mediante guías de identificación (Tabla 2. Aranda, 2000; Chame, 2003), y con la ayuda de los pobladores del lugar.

\begin{tabular}{|c|c|c|c|}
\hline Mesodepredador & Características & $\begin{array}{l}\text { Medidas } \\
\text { de la } \\
\text { excreta } \\
\text { LXA }(\mathrm{cm})\end{array}$ & Forma \\
\hline Canis latrans & $\begin{array}{l}\text { Forma más o menos cilíndrica y } \\
\text { generalmente de color café } \\
\text { oscuro. Pueden aparecer como } \\
\text { trenzadas y terminar en punta } \\
\text { delgada. }\end{array}$ & $\begin{array}{l}\text { L. } 10-20 \\
\text { A. } 2-3.5\end{array}$ & \\
\hline $\begin{array}{l}\text { Urocyon } \\
\text { cinereoargenteus }\end{array}$ & $\begin{array}{l}\text { Forma más o menos cilíndrica y } \\
\text { generalmente de color café } \\
\text { oscuro. }\end{array}$ & $\begin{array}{l}\text { L. } 5-10 \\
\text { A. } 1-2\end{array}$ & \\
\hline $\begin{array}{l}\text { Bassariscus } \\
\text { astutus }\end{array}$ & $\begin{array}{l}\text { Forma más o menos cilíndrica,, } \\
\text { ocasionalmente presentan una } \\
\text { forma trenzada }\end{array}$ & $\begin{array}{l}\text { L. } 5-10 \\
\text { A. } 0.5-1.5\end{array}$ & \\
\hline Lynx rufus & $\begin{array}{l}\text { Forma cilíndrica, color gris claro, } \\
\text { verdoso o negruzco. Pueden } \\
\text { formarse constricciones o } \\
\text { seccionarse. }\end{array}$ & $\begin{array}{l}\text { L. } 10-15 \\
\text { A. } 1.5-2.5\end{array}$ & \\
\hline
\end{tabular}

Tabla 2. Características de las excretas que se consideraron para su identificación. 
Para cada muestra obtenida se registró la siguiente información:

- Número consecutivo durante todo el proyecto.

- Clave de muestra: para tener un registro de cada excreta en la base de datos.

- Fecha de colecta.

- Temporada de colecta: secas o lluvias.

- Sitio de colecta (nombre del paraje según los habitantes del lugar).

- Especie: el nombre de la especie a la cual pertenece la excreta.

- Coordenadas geográficas. Registro de la posición geográfica con un GPS.

- Número(s) de fotografía(s).

- Notas sobre la muestra (Valoración de marcaje):

- Altura sobre el nivel del suelo $(0=$ sobre el suelo, $1=1-4 \mathrm{cms}, 2=>4$ $\mathrm{cms}$ )

- Sobre algún elemento $(0=$ ninguno, $1=$ roca $2=$ =vegetación $)$

- Ubicación colectiva ( $1=$ solitaria $2=$ en letrina monoespecífica, 3 en letrina pluriespecífica)

- Ubicación (1=vereda, 2= camino secundario, 3= camino principal, $4=$ cruce de caminos principales)

- Evidencia ( $0=$ escondida, $1=$ conspicua $)$

- Notas adicionales registradas en campo. 
Por último, cada excreta fue depositada dentro de una bolsa de papel estraza en la que se anotó la clave y el número consecutivo, además se incluyeron los mismos datos en un papel dentro de la bolsa. Las muestras colectadas fueron trasladadas al Laboratorio de Ecología Animal de la UAM-Iztapalapa.

\subsection{Análisis de datos}

Para alcanzar los objetivos propuestos, los datos fueron analizados de la siguiente forma:

\subsubsection{Alimentación}

Para evaluar el contenido en las excretas se procedió de dos formas:

- Peso seco

- Número de veces que el componente apareció en las excretas

En el Laboratorio de Ecología Animal, el material fecal colectado fue puesto dentro de la campana de extracción a temperatura ambiente hasta que alcanzó un peso constante, se determinó así el peso seco. Posteriormente la excreta fue dividida y con ayuda de pinzas y agujas de disección, se separaron los diferentes materiales no digeridos por los mesodepredadores como pelos, huesos, dientes, garras, plumas, escamas, artejos, hojas, semillas, rocas entre otros. Cada componente nutrimental fue pesado para determinar la importancia que cada uno de ellos tiene en la dieta. Tanto para la temporada de secas como de lluvias estos componentes nutrimentales fueron categorizados de la siguiente manera: Vertebrados, Invertebrados, Vegetal e 
Inorgánica. Por último cada componente nutrimental fue colocado dentro de cajas Petri que se rotuló con la clave de la muestra y el número consecutivo.

\subsubsection{Determinación de los componentes de la dieta}

La determinación taxonómica de cada uno de los elementos que conforman las excretas se llevó hasta la el nivel taxonómico más bajo posible, considerando el tipo, cantidad y condición en la que se encontraba el material presente en la excreta.

Para la determinación de restos de los mamíferos, se utilizaron características de pelo (patrones de coloración) material óseo y dientes. Para los reptiles, se utilizaron escamas, garras y material óseo, que fueron comparados con ejemplares de los que se tienen registro en la zona de estudio resguardados en el laboratorio de anfibios y reptiles de la UAM-Iztapalapa. Para el caso de las aves, fueron utilizados plumas y restos óseos que se compararon con material de docencia. Las semillas fueron separadas y asignadas en morfoespecies que fueron comparados con ejemplares de especies de las que se tienen registro en la zona de estudio incluidos en la colección de Mastozoología de la UAM-Iztapalapa

Para cada componente presa (o nutrimento) se determinaron los siguientes valores: por un lado se calculó la frecuencia de ocurrencia $\left(\mathrm{FO}_{i}\right)$, como el número de veces que fue registrada cada especie presa en el total de la muestra.

$$
\mathrm{FO}_{i}(\%)=\left(\mathrm{n}_{i} / \mathrm{N}\right) * 100
$$


Donde:

$\mathrm{FO}_{i}=$ Frecuencia de ocurrencia en porcentaje

$\mathrm{n}_{i}=$ número de excretas que contienen el componente presa $i$

$\mathrm{N}=$ número total de excretas analizadas

\subsubsection{Amplitud de nicho alimenticio}

Amplitud del nicho alimenticio mediante del índice de Levins

$$
B=1 / \sum p i^{2}
$$

Donde:

$p i$ es la proporción del ítem de presa $i$ en la dieta. La proporción pi se calcula dividiendo el número de excretas que contienen el elemento presa $i(\mathrm{n} i)$ entre la suma de todas las excretas que contienen cada ítem de presa $\left(\sum \mathrm{n} i\right)$ :

$$
p i=n i / \sum n i
$$

\subsubsection{Sobreposición de nicho alimenticio}

La sobreposición de nicho alimenticio mediante el índice de sobreposición de Pianka

$$
\boldsymbol{o}=\sum\left(\boldsymbol{p}_{\boldsymbol{i}} \boldsymbol{q}_{\boldsymbol{i}}\right) / \sqrt{\sum \boldsymbol{p} \boldsymbol{i}^{2} \sum} \boldsymbol{q} \boldsymbol{i}^{2}
$$


Donde:

$p_{i}=$ proporción de recurso alimenticio $i$ en las excretas del mesodepredador (por ejemplo, el número de ocurrencias del recurso alimenticio $i$ dividido entre el número total de ocurrencias de todos los recursos alimenticios en todas las excretas del coyote revisadas).

$q_{i}=$ proporción de recurso alimenticio $i$ en otro mesodepredador (por ejemplo, la zorra gris).

\subsubsection{Distribución del espacio}

Para determinar la posible dominancia de alguna de las especies de mesodepredadores sobre las otras se usó un "Índice de marcaje" con el método modificado usado por Barja y List (2006), Barja et al. (2008) y Toriz (2014). El método consiste en evaluar las características relacionadas con la deposición de la excreta: se da valor de 1 cuando la excreta presenta características de ser usada como señal: si se encuentra en un punto por arriba del nivel de suelo (a una altura mayor a $4 \mathrm{~cm}$ ), localizada sobre un cruce de caminos, si se encuentra sobre roca, planta, árbol o arbusto y si es conspicua desde el punto de vista de los animales. De este modo, si una excreta no presenta ninguna de estas características se le asigna un índice de marcaje nulo, pero si presenta tres de estas características su valor de marcaje es alto (Tabla 3). 


\begin{tabular}{|l|l|}
\hline $\begin{array}{l}\text { Puntuación } \\
\text { acumulada }\end{array}$ & $\begin{array}{l}\text { Índice de } \\
\text { marcaje }\end{array}$ \\
\hline 0 & Nulo \\
\hline 1 & Bajo \\
\hline 2 & Medio \\
\hline 3 & Alto \\
\hline
\end{tabular}

Tabla 3. Valores de marcaje.

\subsubsection{1 Índice de asociación espacial}

Para determinar el grado de sobreposición espacial entre los mesodepredadores se usó un índice de asociación espacial. Los transectos utilizados para el muestreo fueron divididos en cuadrantes (cuatro cuadrantes por cada transecto, dando un total de veinticuatro cuadrantes), dentro de los que se contó el número de excretas de cada una de las especies presentes. En una tabla de contingencia de $2 \times 2$ para cada uno de los pares de especies, se sumaron los cuadrantes de la siguiente manera:
A. Cuadrantes en donde se encuentran dos especies (p. ej. coyote y zorra).
B. Cuadrantes en donde sólo se encuentra la especie A (p. ej. coyote).
C. Cuadrantes en donde sólo se encuentra la especie B (p. ej. zorra).
D. Cuadrantes en donde no se encuentra ninguna especie. 


\begin{tabular}{|c|c|c|c|c|}
\hline \multicolumn{2}{|c|}{} & \multicolumn{2}{c|}{ Especie B } & \multirow{2}{*}{} \\
\cline { 3 - 5 } & & Presente & Ausente & \\
\hline \multirow{2}{*}{ Especie A } & Presente & a & $b$ & a + b \\
\cline { 3 - 5 } & Ausente & $c$ & $d$ & $c+d$ \\
\hline & & a c c & b + c & T \\
\hline
\end{tabular}

Posteriormente se determinó el coeficiente de asociación (C), utilizando la fórmula correspondiente dependiendo de la relación numérica dentro de la tabla de contingencia (Cole 1949).

- Cuando $a d \geq b c \quad C=\frac{a d-b c}{(a+b)(b+d)}$

- Cuando bc $>$ ad

$$
\text { y } d \geq a \quad C=\frac{a d-b c}{(a+b)(a+c)}
$$

- Cuando bc $>$ ad

$$
\text { y } a>d \quad C=\frac{a d-b c}{(b+d)(c+d)}
$$

\subsubsection{Utilización temporal del espacio}

Dado que las cámaras trampa registran con precisión la hora en que los animales se encuentran activos, se realizó un análisis con estadística circular sobre la presencia temporal los mesodepredadores en los diferentes transectos. 


\section{RESULTADOS}

Los resultados del presente estudio están basados en el análisis de 349 excretas colectadas de cuatro especies de mamíferos de talla media. De éstas, 241 fueron colectadas en la temporada de secas y 108 en la temporada de lluvias. El 33\% fueron de C. latrans (coyote), $6 \%$ de Lynx rufus (lince), 43\% de Urocyon cinereoargenteus (zorra gris) y el $18 \%$ de Bassariscus astutus (cacomixtle; Tabla 4).

\begin{tabular}{|c|c|c|c|c|c|c|c|c|c|c|}
\hline & & & & & alida: & & & & & \\
\hline & 1 & 2 & 3 & 4 & 5 & 6 & 7 & 8 & 9 & \\
\hline Especie/Temporada & $\begin{array}{c}\text { dic- } \\
15 \\
\end{array}$ & $\begin{array}{c}\text { ene- } \\
16\end{array}$ & $\begin{array}{c}\text { mar- } \\
16 \\
\end{array}$ & $\begin{array}{c}\text { may- } \\
16 \\
\end{array}$ & $\begin{array}{l}\text { jun- } \\
16 \\
\end{array}$ & $\begin{array}{c}\text { ago- } \\
16 \\
\end{array}$ & $\begin{array}{c}\text { oct- } \\
16 \\
\end{array}$ & $\begin{array}{c}\text { nov- } \\
16\end{array}$ & $\begin{array}{l}\text { feb- } \\
17 \\
\end{array}$ & Total \\
\hline $\begin{array}{l}\text { Canis } \\
\text { latrans } \\
\text { Lvnx }\end{array}$ & 5 & 22 & 15 & 8 & 6 & 7 & 4 & 30 & 19 & 116 \\
\hline $\begin{array}{l}\text { rufus } \\
\text { Urocyon }\end{array}$ & 0 & 2 & 2 & 0 & 6 & 2 & 0 & 1 & 6 & 19 \\
\hline $\begin{array}{l}\text { cinereoargenteus } \\
\text { Bassariscus }\end{array}$ & 10 & 15 & 20 & 18 & 10 & 9 & 5 & 36 & 28 & 151 \\
\hline astutus & 3 & 13 & 2 & 17 & 1 & 6 & 9 & 7 & 5 & 63 \\
\hline Total de excretas & 18 & 52 & 39 & 43 & 23 & 24 & 18 & 74 & 58 & 349 \\
\hline
\end{tabular}

Tabla 4. Total de excretas colectadas de las diferentes especies de mesodepredadores, por salida, durante la temporada de secas (en color morado) y lluvias (en color verde). 


\subsection{Alimentación de los mesodepredadores}

\subsubsection{Alimentación de Canis latrans}

Los resultados del análisis del porcentaje de peso seco revelaron que el coyote basa más del $90 \%$ de su dieta en dos componentes que alterna dependiendo la temporada del año (gráfica 2 y 3). Durante la temporada de secas, su principal fuente de alimento fueron los vertebrados que de acuerdo con los datos de ocurrencia evidenciaron la presencia de restos óseos de lagomorfos y roedores como su fuente básica de proteínas. Así mismo incorpora a su dieta 8 morfoespecies de semillas, de éstas, tres juegan un papel importante (morfo 1, morfo 4 y morfo 12 respectivamente) pues están presentes a lo largo del año (Tabla 5). Para la temporada de lluvias de acuerdo con los datos de peso seco Canis latrans explota primordialmente recursos vegetales (gráfica 2). A lo largo de las lluvias sólo incorpora la morfoespecie 11 con un porcentaje muy reducido y que alterna con las tres consumidas en la temporada de secas (Tabla 5). Con respecto a los vertebrados en este período, es notable la disminución de los restos de óseos de lagomorfos en sus excretas y el pequeño incremento de roedores, aves y reptiles en su dieta (Tabla 5). 


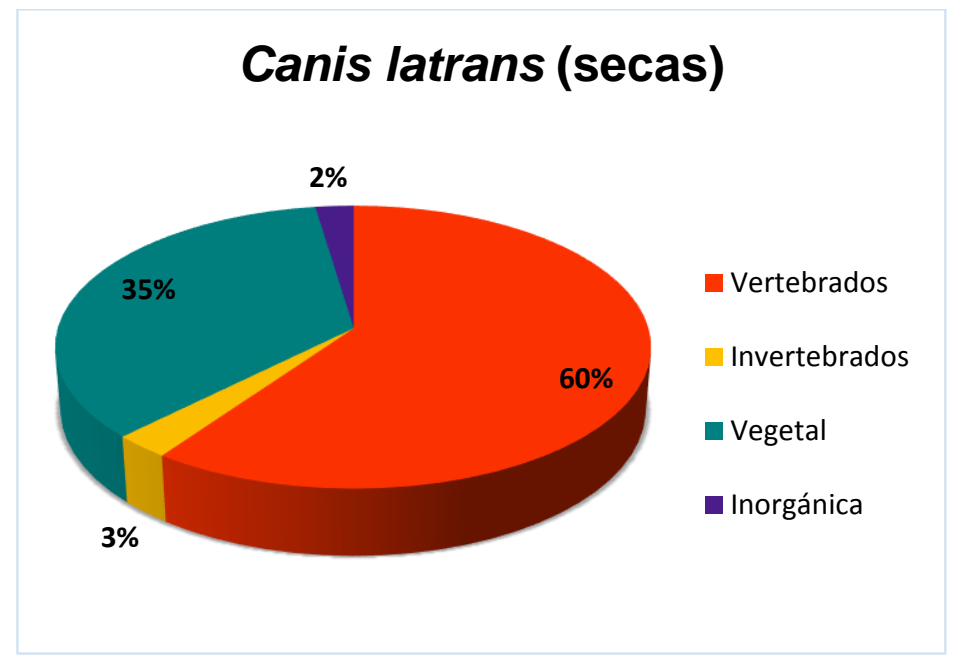

Gráfica 2. Porcentaje de peso seco de las diferentes categorías alimenticias en las excretas de Canis latrans durante la temporada de secas.

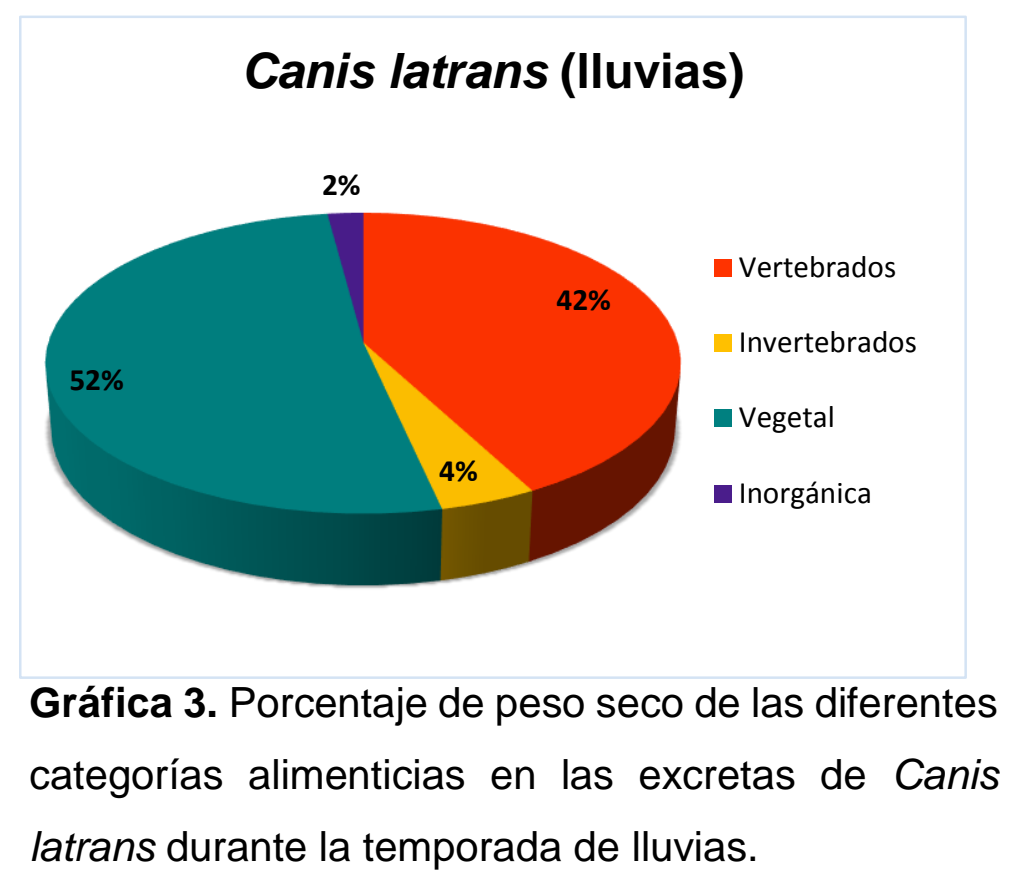


Tabla 5. La ocurrencia de ítems de presa encontrados en 116 excretas de Canis latrans, categorizadas en temporada de secas y lluvias, identificadas hasta el nivel taxonómico más bajo posible. Dentro de cada categoría, $\mathrm{N}=$ número total de excretas, $\mathrm{ni}=$ número de excretas que contienen cada ítem, $\mathrm{FO}=$ frecuencia de ocurrencia, y $\mathrm{PO}=$ porcentaje de ocurrencia.

\begin{tabular}{|c|c|c|c|c|c|c|c|c|c|}
\hline & \multicolumn{3}{|c|}{ Secas } & \multicolumn{3}{|c|}{ Lluvias } & \multicolumn{3}{|c|}{ Anual } \\
\hline & $\mathrm{N}=$ & 91 & & $\mathrm{~N}=$ & 25 & & $\mathrm{~N}=$ & 116 & \\
\hline & ni & $\mathrm{FO}$ & $\mathrm{PO}$ & $\mathrm{Ni}$ & FO & $\mathrm{PO}$ & ni & FO & $\mathrm{PO}$ \\
\hline \multicolumn{10}{|l|}{ Elemento } \\
\hline Mamíferos & 53 & 58.24 & 27.60 & 8 & 32.00 & 22.22 & 61 & 52.59 & 26.75 \\
\hline Rodentia & 20 & 21.98 & 10.42 & 5 & 20.00 & 13.89 & 25 & 21.55 & 10.96 \\
\hline Heteromys irroratus & 6 & 6.59 & 3.13 & 1 & 4.00 & 2.78 & 7 & 6.03 & 3.07 \\
\hline Reithrodontomys & 3 & 3.30 & 1.56 & 2 & 8.00 & 5.56 & 5 & 4.31 & 2.19 \\
\hline Dipodomys & 3 & 3.30 & 1.56 & 0 & 0.00 & 0.00 & 3 & 2.59 & 1.32 \\
\hline No identifcados & 8 & 8.79 & 4.17 & 2 & 8.00 & 5.56 & 10 & 8.62 & 4.39 \\
\hline Lagomorpha & 33 & 36.26 & 17.19 & 3 & 12.00 & 8.33 & 36 & 31.03 & 15.79 \\
\hline Reptiles & 8 & 8.79 & 4.17 & 2 & 8.00 & 5.56 & 10 & 8.62 & 4.39 \\
\hline Iguanidae & 4 & 4.40 & 2.08 & 1 & 4.00 & 2.78 & 5 & 4.31 & 2.19 \\
\hline Teiidae & 0 & 0.00 & 0.00 & 1 & 4.00 & 2.78 & 1 & 0.86 & 0.44 \\
\hline No identificados & 4 & 4.40 & 2.08 & 0 & 0.00 & 0.00 & 4 & 3.45 & 1.75 \\
\hline Aves & 6 & 6.59 & 3.13 & 2 & 8.00 & 5.56 & 8 & 6.90 & 3.51 \\
\hline Invertebrados & 16 & 17.58 & 8.33 & 3 & 12.00 & 8.33 & 19 & 16.38 & 8.33 \\
\hline Coleoptera & 3 & 3.30 & 1.56 & 1 & 4.00 & 2.78 & 4 & 3.45 & 1.75 \\
\hline Hemiptera & 2 & 2.20 & 1.04 & 0 & 0.00 & 0.00 & 2 & 1.72 & 0.88 \\
\hline Orthoptera & 10 & 10.99 & 5.21 & 1 & 4.00 & 2.78 & 11 & 9.48 & 4.82 \\
\hline No identificados & 1 & 1.10 & 0.52 & 1 & 4.00 & 2.78 & 2 & 1.72 & 0.88 \\
\hline Semillas & 101 & 110.99 & 52.60 & 14 & 56.00 & 38.89 & 115 & 99.14 & 50.44 \\
\hline morfoespecie 1 & 32 & 35.16 & 16.67 & 5 & 20.00 & 13.89 & 37 & 31.90 & 16.23 \\
\hline morfoespecie 2 & 15 & 16.48 & 7.81 & 0 & 0.00 & 0.00 & 15 & 12.93 & 6.58 \\
\hline morfoespecie 3 & 6 & 6.59 & 3.13 & 0 & 0.00 & 0.00 & 6 & 5.17 & 2.63 \\
\hline morfoespecie 4 & 31 & 34.07 & 16.15 & 2 & 8.00 & 5.56 & 33 & 28.45 & 14.47 \\
\hline morfoespecie 6 & 2 & 2.20 & 1.04 & 0 & 0.00 & 0.00 & 2 & 1.72 & 0.88 \\
\hline morfoespecie 9 & 1 & 1.10 & 0.52 & 0 & 0.00 & 0.00 & 1 & 0.86 & 0.44 \\
\hline morfoespecie 10 & 2 & 2.20 & 1.04 & 0 & 0.00 & 0.00 & 2 & 1.72 & 0.88 \\
\hline morfoespecie 11 & 0 & 0.00 & 0.00 & 1 & 4.00 & 2.78 & 1 & 0.86 & 0.44 \\
\hline morfoespecie 12 & 12 & 13.19 & 6.25 & 6 & 24.00 & 16.67 & 18 & 15.52 & 7.89 \\
\hline No orgánico & 8 & 8.79 & 4.17 & 7 & 28.00 & 19.44 & 15 & 12.93 & 6.58 \\
\hline Amplitud de nicho & & 8.50 & & & 7.95 & & & 9.19 & \\
\hline
\end{tabular}




\subsection{Alimentación de Urocyon cinereoargenteus}

El porcentaje de peso seco mostró que sin importar la temporada del año, y con más del $94 \%$ de consumo, la zorra gris basó su dieta en elementos de origen vegetal, complementándola con vertebrados e invertebrados (gráfica 4 y 5). Anualmente consumió nueve diferentes morfoespecies de semillas de las cuales, cuatro están presentes en su dieta a lo largo del año (morfo 1, morfo 3, morfo 4 y morfo 12) siendo la morfoespecie 12 la más consumida (Tabla 6). Durante la temporada de secas, incorporó a su dieta 8 morfoespecies de semillas, de éstas 4 juegan un papel importante (morfo 1, morfo 3 , morfo 4 y morfo 12). Con respecto a los vertebrados, la zorra gris presentó un consumo de pequeños roedores y sólo en esta temporada fueron encontrados restos óseos de lagomorfos. Dentro de los invertebrados se encontró una baja presencia de coleópteros, hemípteros y ortópteros. Para la temporada de lluvias incorpora en su dieta las morfoespecies 7 (con un porcentaje muy reducido) y 10 (con un porcentaje considerable) que alterna con las cuatro consumidas en la época de secas (Tabla 6). Con respecto a los vertebrados en este período, es notable la disminución de los restos de óseos de lagomorfos en sus excretas y el pequeño incremento de reptiles (Tabla 6). De igual manera incorpora insectos como coleópteros y ortópteros aunque en bajo porcentaje. 


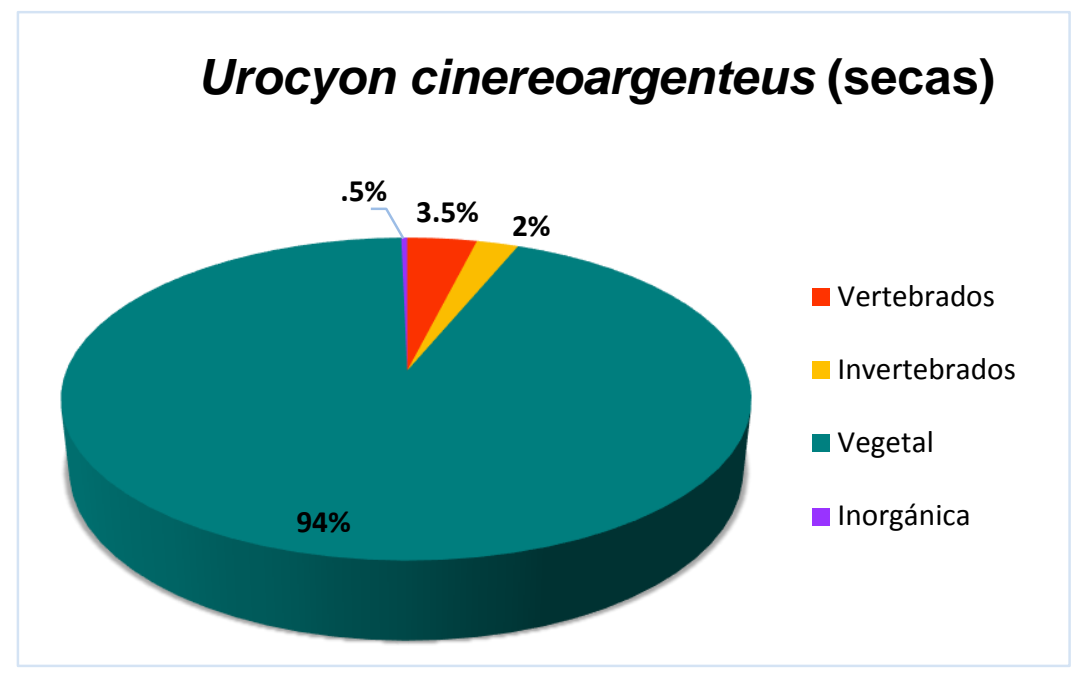

Gráfica 4. Porcentaje de peso seco de las diferentes categorías alimenticias en las excretas de Urocyon cinereoargenteus durante la temporada de secas.

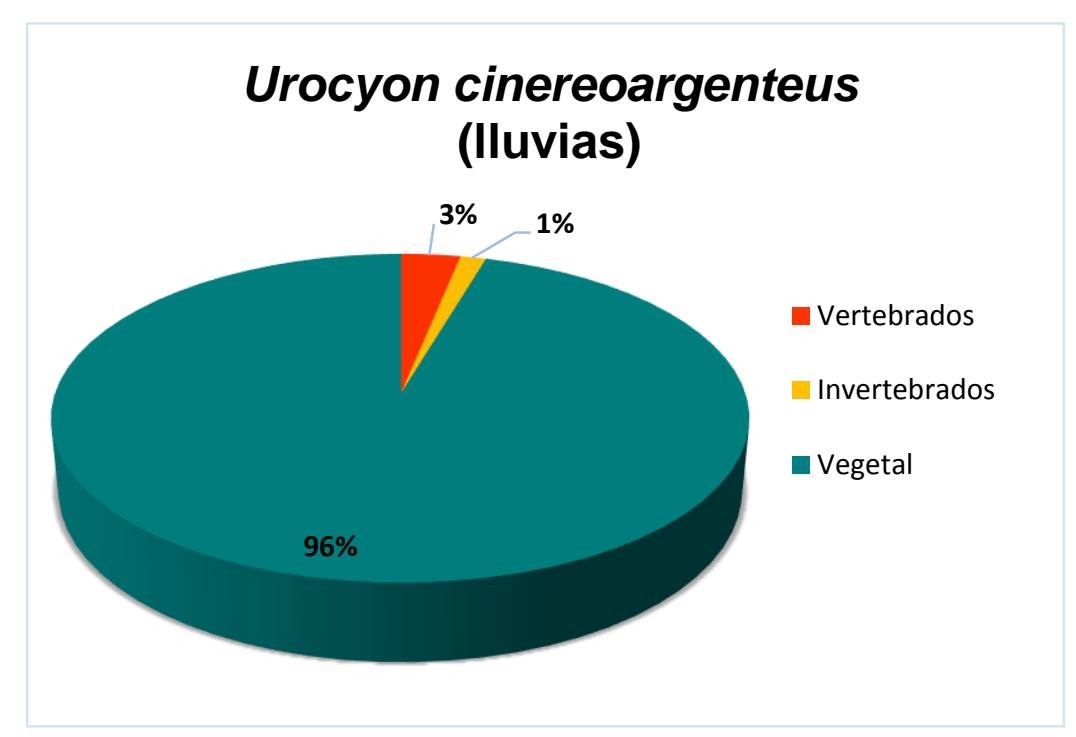

Gráfica 5. Porcentaje de peso seco de las diferentes categorías alimenticias en las excretas de Urocyon cinereoargenteus durante la temporada de lluvias. 
Tabla 6. La ocurrencia de ítems de presa encontrados en 151 excretas de Urocyon cinereoargenteus, categorizadas en temporada de secas y lluvias identificadas hasta el nivel taxonómico más bajo posible. Dentro de cada categoría, $\mathrm{N}$ = número total de excretas, $\mathrm{ni}=$ número de excretas que contienen cada ítem, $\mathrm{FO}=$ frecuencia de ocurrencia, y $\mathrm{PO}=$ porcentaje de ocurrencia.

\begin{tabular}{|c|c|c|c|c|c|c|c|c|c|}
\hline & \multicolumn{3}{|c|}{ Secas } & \multicolumn{3}{|c|}{ Lluvias } & \multicolumn{3}{|c|}{ Anual } \\
\hline & $\mathrm{N}=$ & 109 & & $\mathrm{~N}=$ & 42 & & $\mathrm{~N}=$ & 151 & \\
\hline & ni & FO & $\mathrm{PO}$ & $\mathrm{Ni}$ & FO & $\mathrm{PO}$ & $\mathrm{Ni}$ & FO & $\mathrm{PO}$ \\
\hline \multicolumn{10}{|l|}{ Elemento } \\
\hline Mamíferos & 12 & 11.01 & 7.32 & 2 & 4.76 & 4.00 & 14 & 9.27 & 6.54 \\
\hline Rodentia & 9 & 8.26 & 5.49 & 2 & 4.76 & 4.00 & 11 & 7.28 & 5.14 \\
\hline Heteromys irroratus & 1 & 0.92 & 0.61 & 0 & 0.00 & 0.00 & 1 & 0.66 & 0.47 \\
\hline Reithrodontomys & 2 & 1.83 & 1.22 & 0 & 0.00 & 0.00 & 2 & 1.32 & 0.93 \\
\hline Dipodomys & 3 & 2.75 & 1.83 & 0 & 0.00 & 0.00 & 3 & 1.99 & 1.40 \\
\hline Peromyscus & 2 & 1.83 & 1.22 & 0 & 0.00 & 0.00 & 2 & 1.32 & 0.93 \\
\hline No identifcados & 1 & 0.92 & 0.61 & 2 & 4.76 & 4.00 & 3 & 1.99 & 1.40 \\
\hline Lagomorpha & 3 & 2.75 & 1.83 & 0 & 0.00 & 0.00 & 3 & 1.99 & 1.40 \\
\hline Reptiles & 0 & 0.00 & 0.00 & 2 & 4.76 & 4.00 & 2 & 1.32 & 0.93 \\
\hline Iguanidae & 0 & 0.00 & 0.00 & 1 & 2.38 & 2.00 & 1 & 0.66 & 0.47 \\
\hline No identificados & 0 & 0.00 & 0.00 & 1 & 2.38 & 2.00 & 1 & 0.66 & 0.47 \\
\hline Aves & 2 & 1.83 & 1.22 & 1 & 2.38 & 2.00 & 3 & 1.99 & 1.40 \\
\hline Invertebrados & 16 & 14.68 & 9.76 & 6 & 14.29 & 12.00 & 22 & 14.57 & 10.28 \\
\hline Coleoptera & 4 & 3.67 & 2.44 & 2 & 4.76 & 4.00 & 6 & 3.97 & 2.80 \\
\hline Hemiptera & 1 & 0.92 & 0.61 & 0 & 0.00 & 0.00 & 1 & 0.66 & 0.47 \\
\hline Orthoptera & 6 & 5.50 & 3.66 & 2 & 4.76 & 4.00 & 8 & 5.30 & 3.74 \\
\hline No identificados & 5 & 4.59 & 3.05 & 2 & 4.76 & 4.00 & 7 & 4.64 & 3.27 \\
\hline Semillas & 130 & 119.27 & 79.27 & 39 & 92.86 & 78.00 & 169 & 111.92 & 78.97 \\
\hline morfoespecie 1 & 29 & 26.61 & 17.68 & 14 & 33.33 & 28.00 & 43 & 28.48 & 20.09 \\
\hline morfoespecie 2 & 7 & 6.42 & 4.27 & 0 & 0.00 & 0.00 & 7 & 4.64 & 3.27 \\
\hline morfoespecie 3 & 24 & 22.02 & 14.63 & 1 & 2.38 & 2.00 & 25 & 16.56 & 11.68 \\
\hline morfoespecie 4 & 19 & 17.43 & 11.59 & 2 & 4.76 & 4.00 & 21 & 13.91 & 9.81 \\
\hline morfoespecie 6 & 2 & 1.83 & 1.22 & 0 & 0.00 & 0.00 & 2 & 1.32 & 0.93 \\
\hline morfoespecie 7 & 0 & 0.00 & 0.00 & 1 & 2.38 & 2.00 & 1 & 0.66 & 0.47 \\
\hline morfoespecie 8 & 2 & 1.83 & 1.22 & 0 & 0.00 & 0.00 & 2 & 1.32 & 0.93 \\
\hline morfoespecie 10 & 0 & 0.00 & 0.00 & 6 & 14.29 & 12.00 & 6 & 3.97 & 2.80 \\
\hline morfoespecie 12 & 47 & 43.12 & 28.66 & 15 & 35.71 & 30.00 & 62 & 41.06 & 28.97 \\
\hline No orgánico & 4 & 3.67 & 2.44 & 0 & 0.00 & 0.00 & 4 & 2.65 & 1.87 \\
\hline Amplitud de nicho & & 6.02 & & & 4.28 & & & 5.88 & \\
\hline
\end{tabular}




\subsubsection{Alimentación de Bassariscus astutus}

El porcentaje de peso seco mostró que a lo largo del año y sin importar la estacionalidad, el cacomixtle basó su dieta en elementos vegetales (Gráficas 6 y 7), siendo cuatro morfoespecies de semillas las más consumidas en ambas temporadas (morfo 1, morfo 3, morfo 4 y morfo 7 ). Dentro de la frecuencia de ocurrencia los invertebrados (en mayor porcentaje los coleópteros) complementan su dieta durante todo el año (Tabla 7). Durante la temporada de secas, consumió 7 diferentes morfoespecies de semillas, de estas, sólo dos son importantes (morfo 1 y morfo 3). De acuerdo con los datos de ocurrencia, su fuente básica de proteínas para esta temporada fueron pequeños vertebrados como son las aves y los roedores. Para la temporada de lluvias se encontraron presentes 6 de las 8 morfoespecies consumidas por el cacomixtle, siendo cuatro las morfoespecies más importantes (morfo 1, morfo 3, morfo 4 y morfo 7). En esta temporada se presentó un aumento de invertebrados, de los que coleópteros y ortópteros fueron los más frecuentes. Con respecto a los vertebrados es notable la disminución de restos óseos de aves y roedores pues sólo fueron encontrados restos de reptiles (Tabla 7). 


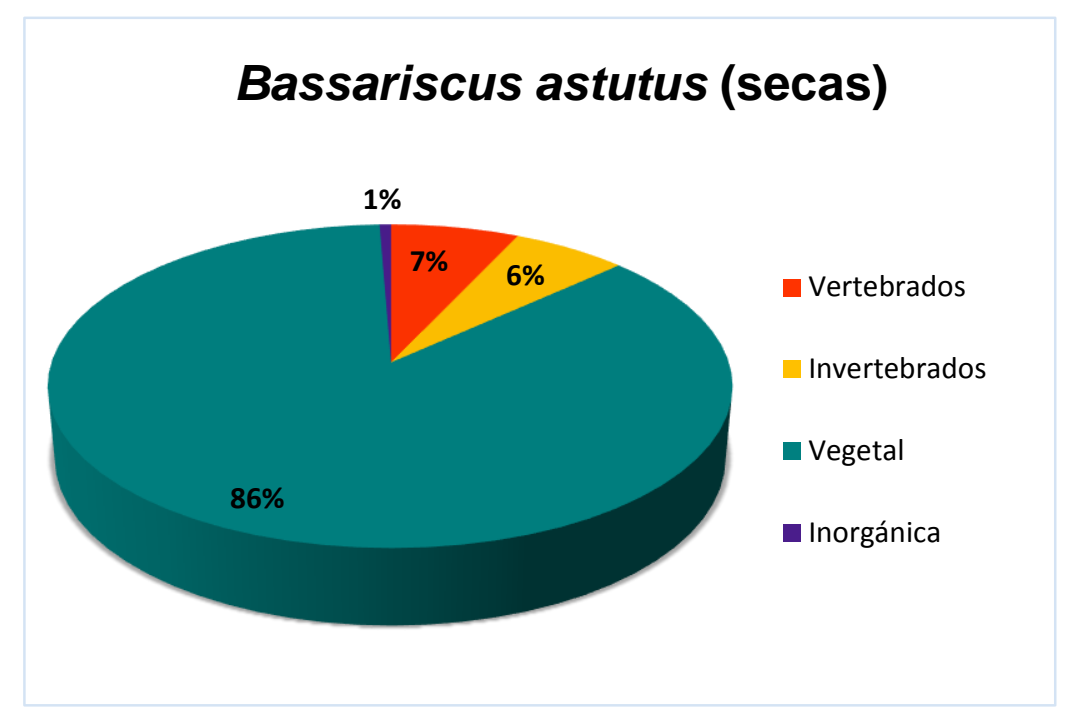

Gráfica 6. Porcentaje de peso seco de las diferentes categorías alimenticias en las excretas de Bassariscus astutus durante la temporada de secas.

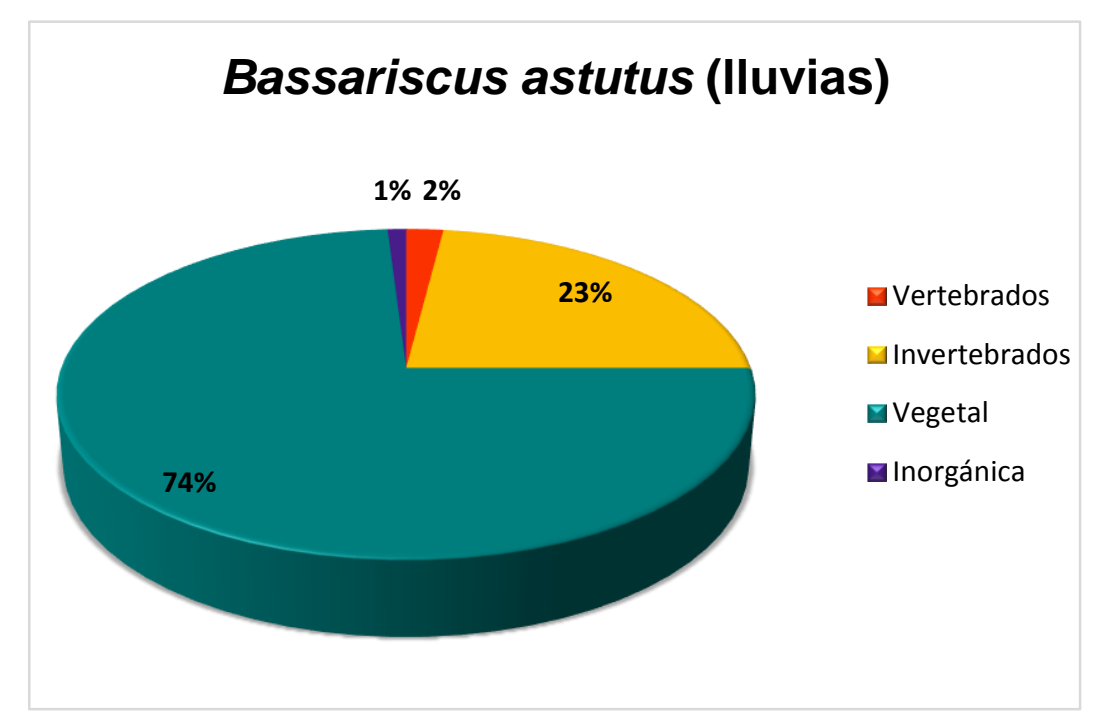

Gráfica 7. Porcentaje de peso seco de las diferentes categorías alimenticias en las excretas de Bassariscus astutus durante la temporada de lluvias. 
Tabla 7. La ocurrencia de ítems de presa encontrados en 63 excretas de Bassariscus astutus, categorizadas en temporada de secas y lluvias, identificadas hasta el nivel taxonómico más bajo posible. Dentro de cada categoría, $\mathrm{N}=$ número total de excretas, $\mathrm{ni}=$ número de excretas que contienen cada ítem, $\mathrm{FO}=$ frecuencia de ocurrencia, y $\mathrm{PO}=$ porcentaje de ocurrencia.

\begin{tabular}{|c|c|c|c|c|c|c|c|c|c|}
\hline & \multicolumn{3}{|c|}{ Secas } & \multicolumn{3}{|c|}{ Lluvias } & \multicolumn{3}{|c|}{ Anual } \\
\hline & $\mathrm{N}=$ & 30 & & $\mathrm{~N}=$ & 33 & & $\mathrm{~N}=$ & 63 & \\
\hline & $\mathrm{ni}$ & $\mathrm{FO}$ & $\mathrm{PO}$ & ni & $\mathrm{FO}$ & $\mathrm{PO}$ & ni & $\mathrm{FO}$ & $\mathrm{PO}$ \\
\hline \multicolumn{10}{|l|}{ Elemento } \\
\hline Mamíferos & 4 & 13.33 & 8 & 0 & 0 & 0 & 4 & 6.35 & 4.08 \\
\hline Rodentia & 4 & 13.33 & 8 & 0 & 0 & 0 & 4 & 6.35 & 4.08 \\
\hline Heteromys irroratus & 1 & 3.33 & 2 & 0 & 0 & 0 & 1 & 1.59 & 1.02 \\
\hline No identifcados & 3 & 10.00 & 6 & 0 & 0 & 0 & 3 & 4.76 & 3.06 \\
\hline Reptiles & 0 & 0.00 & 0 & 1 & 3.03 & 2.08 & 1 & 1.59 & 1.02 \\
\hline No identificados & 0 & 0.00 & 0 & 1 & 3.03 & 2.08 & 1 & 1.59 & 1.02 \\
\hline Aves & 2 & 6.67 & 4 & 0 & 0.00 & 0.00 & 2 & 3.17 & 2.04 \\
\hline Invertebrados & 11 & 36.67 & 22 & 17 & 51.52 & 35.42 & 28 & 44.44 & 28.57 \\
\hline Coleoptera & 6 & 20.00 & 12 & 11 & 33.33 & 22.92 & 17 & 26.98 & 17.35 \\
\hline Hemiptera & 1 & 3.33 & 2 & 0 & 0.00 & 0.00 & 1 & 1.59 & 1.02 \\
\hline Orthoptera & 2 & 6.67 & 4 & 6 & 18.18 & 12.50 & 8 & 12.70 & 8.16 \\
\hline No identificados & 2 & 6.67 & 4 & 0 & 0.00 & 0.00 & 2 & 3.17 & 2.04 \\
\hline Semillas & 31 & 103.33 & 62 & 27 & 81.82 & 56.25 & 58 & 92.06 & 59.18 \\
\hline morfoespecie 1 & 12 & 40.00 & 24 & 11 & 33.33 & 22.92 & 23 & 36.51 & 23.47 \\
\hline morfoespecie 2 & 1 & 3.33 & 2 & 2 & 6.06 & 4.17 & 3 & 4.76 & 3.06 \\
\hline morfoespecie 3 & 11 & 36.67 & 22 & 7 & 21.21 & 14.58 & 18 & 28.57 & 18.37 \\
\hline morfoespecie 4 & 2 & 6.67 & 4 & 3 & 9.09 & 6.25 & 5 & 7.94 & 5.10 \\
\hline morfoespecie 7 & 2 & 6.67 & 4 & 3 & 9.09 & 6.25 & 5 & 7.94 & 5.10 \\
\hline morfoespecie 8 & 1 & 3.33 & 2 & 0 & 0.00 & 0.00 & 1 & 1.59 & 1.02 \\
\hline morfoespecie 10 & 2 & 6.67 & 4 & 0 & 0.00 & 0.00 & 2 & 3.17 & 2.04 \\
\hline morfoespecie 12 & 0 & 0.00 & 0 & 1 & 3.03 & 2.08 & 1 & 1.59 & 1.02 \\
\hline No orgánico & 2 & 6.67 & 4 & 3 & 9.09 & 6.25 & 5 & 7.94 & 5.10 \\
\hline Amplitud de nicho & & 6.15 & & & 6.03 & & & 6.47 & \\
\hline
\end{tabular}




\subsubsection{Alimentación de Lynx rufus}

Los resultados del porcentaje de peso seco mostraron que sin importar la temporada del año, y con más del $90 \%$ de consumo, el lince basó su dieta en elementos dentro de la categoría de vertebrados, complementándola con elementos de origen vegetal. También hay presencia de invertebrados pero en proporciones muy bajas (Gráfica 8 y 9). De acuerdo con los datos de frecuencia de ocurrencia durante la temporada de secas, su fuente básica de proteínas la constituyeron los lagomorfos, complementándola con roedores y reptiles en bajo porcentaje. Así mismo incorpora a su dieta 2 morfoespecies de semillas (morfo 1 y morfo 3 ). Durante la temporada de lluvias los lagomorfos continúan siendo su principal fuente de alimentación, que de igual manera complementa con roedores y reptiles. Para esta temporada incorpora la morfoespecie 12 con un porcentaje muy reducido, que alterna con la morfoespecie 1 (Tabla 8). 


\section{Lynx rufus (secas)}

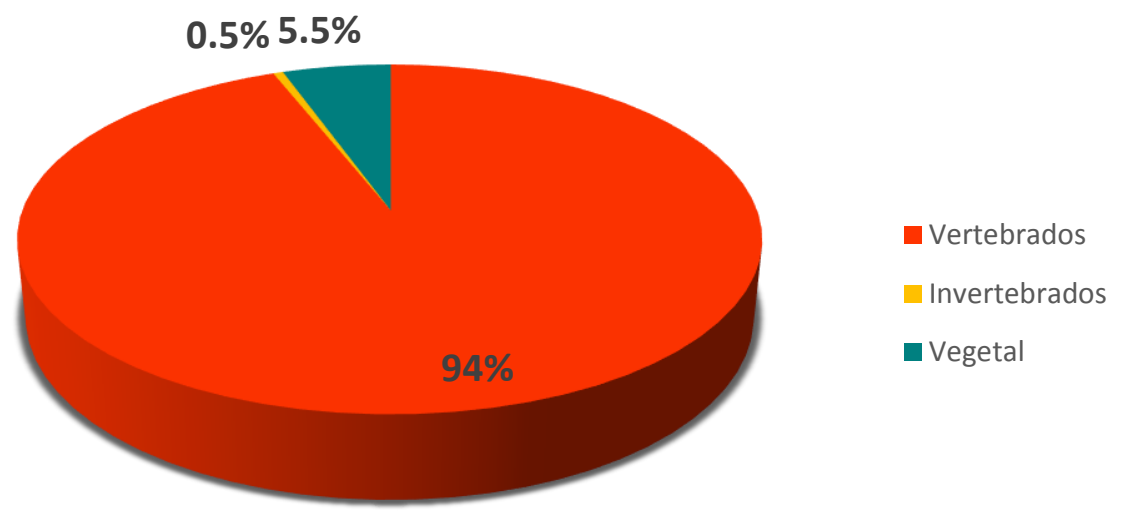

Gráfica 8. Porcentaje de peso seco de las diferentes categorías alimenticias en las excretas de Lynx rufus durante la temporada de secas.

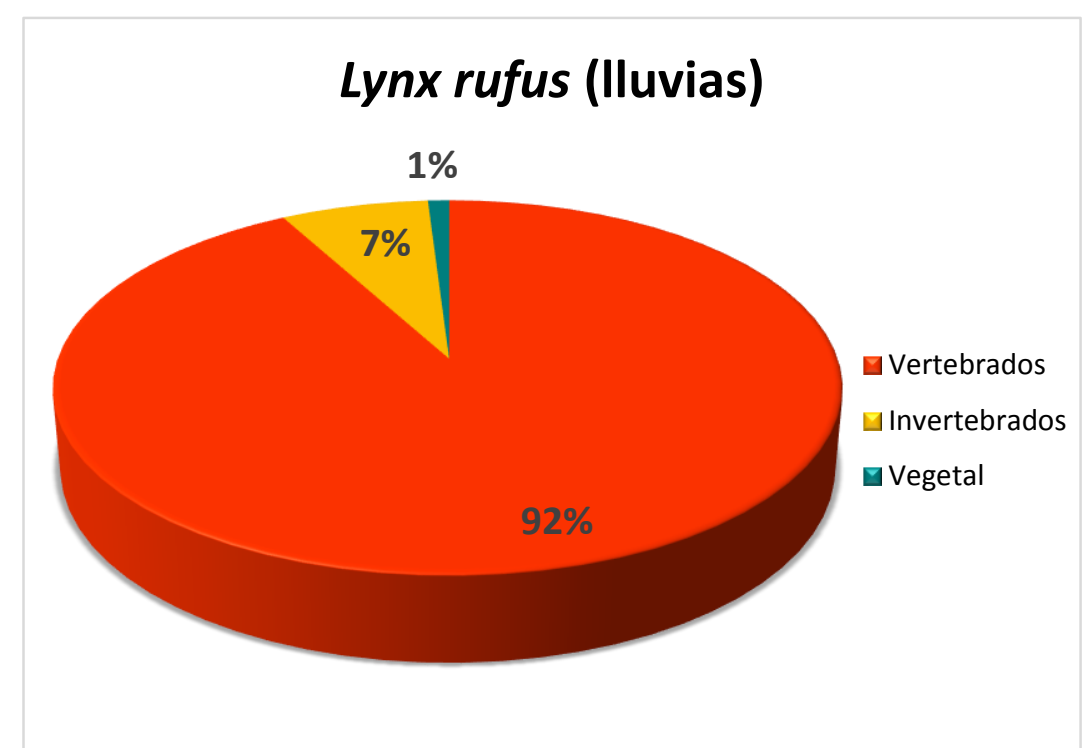

Gráfica 9. Porcentaje de peso seco de las diferentes categorías alimenticias en las excretas de Lynx rufus durante la temporada de lluvias. 
Tabla 8. La ocurrencia de ítems de presa encontrados en 19 excretas de Lynx rufus, categorizadas en temporada de secas y lluvias, identificadas hasta el nivel taxonómico más bajo posible. Dentro de cada categoría, $\mathrm{N}=$ número total de excretas, $\mathrm{ni}=$ número de excretas que contienen cada ítem, $\mathrm{FO}=$ frecuencia de ocurrencia, y $\mathrm{PO}=$ porcentaje de ocurrencia.

\begin{tabular}{|c|c|c|c|c|c|c|c|c|c|}
\hline & \multicolumn{3}{|c|}{ Secas } & \multicolumn{3}{|c|}{ Lluvias } & \multicolumn{3}{|c|}{ Anual } \\
\hline & $\mathrm{N}=$ & 11 & & $\mathrm{~N}=$ & 8 & & $\mathrm{~N}=$ & 19 & \\
\hline & ni & $\mathrm{FO}$ & $\mathrm{PO}$ & $\mathrm{ni}$ & $\mathrm{FO}$ & $\mathrm{PO}$ & ni & FO & $\mathrm{PO}$ \\
\hline \multicolumn{10}{|l|}{ Elemento } \\
\hline Mamíferos & 12 & 109.09 & 75.00 & 8 & 100.00 & 66.67 & 20 & 105.26 & 71.43 \\
\hline $\begin{array}{l}\text { Rodentia } \\
\text { Heteromys }\end{array}$ & 1 & 9.09 & 6.25 & 1 & 12.50 & 8.33 & 2 & 10.53 & 7.14 \\
\hline irroratus & 0 & 0.00 & 0.00 & 1 & 12.50 & 8.33 & 1 & 5.26 & 3.57 \\
\hline Peromyscus & 1 & 9.09 & 6.25 & 0 & 0.00 & 0.00 & 1 & 5.26 & 3.57 \\
\hline Lagomorpha & 11 & 100.00 & 68.75 & 7 & 87.50 & 58.33 & 18 & 94.74 & 64.29 \\
\hline Reptiles & 1 & 9.09 & 6.25 & 1 & 12.50 & 8.33 & 2 & 10.53 & 7.14 \\
\hline Iguanidae & 1 & 9.09 & 6.25 & 1 & 12.50 & 8.33 & 2 & 10.53 & 7.14 \\
\hline Invertebrados & 1 & 9.09 & 6.25 & 1 & 12.50 & 8.33 & 2 & 10.53 & 7.14 \\
\hline Semillas & 2 & 18.18 & 12.50 & 2 & 25.00 & 16.67 & 4 & 21.05 & 14.29 \\
\hline morfoespecie 1 & 1 & 9.09 & 6.25 & 1 & 12.50 & 8.33 & 2 & 10.53 & 7.14 \\
\hline morfoespecie 3 & 1 & 9.09 & 6.25 & 0 & 0.00 & 0.00 & 1 & 5.26 & 3.57 \\
\hline morfoespecie 12 & 0 & 0.00 & 0.00 & 1 & 12.50 & 8.33 & 1 & 5.26 & 3.57 \\
\hline Amplitud de nicho & & 1.8 & & & 2.28 & & & 2.01 & \\
\hline
\end{tabular}

\subsubsection{Amplitud de nicho de alimentación}

De acuerdo a los resultados obtenidos de amplitud de nicho para cada uno de los mesodepredadores a lo largo del año, el coyote presentó los valores más altos (9.19), seguido por el cacomixtle (6.47), la zorra gris (5.88) y lince con (2.01). Es interesante notar que los mesodepredadores de mayor talla mostraron una amplitud de nicho contrastante. Pues durante las secas la amplitud de nicho del coyote fue de 8.50 en tanto el del lince de 1.8. El mismo patrón se presentó durante la estación de lluvias, el coyote tuvo una amplitud de 7.9, mientras que el lince con 2.3 fue más estrecho. 
En la curva de acumulación de especies anual, realizada en el paquete estadístico EstimateS 9.1.0, se puede observar la variación en la cantidad de especies que cada mesodepredador consumió a lo largo del año. Mientras que el lince incorporó en su dieta cinco categorías nutrimentales, el coyote incorporó en su dieta más de quince componentes nutrimentales (Gráfica 10).

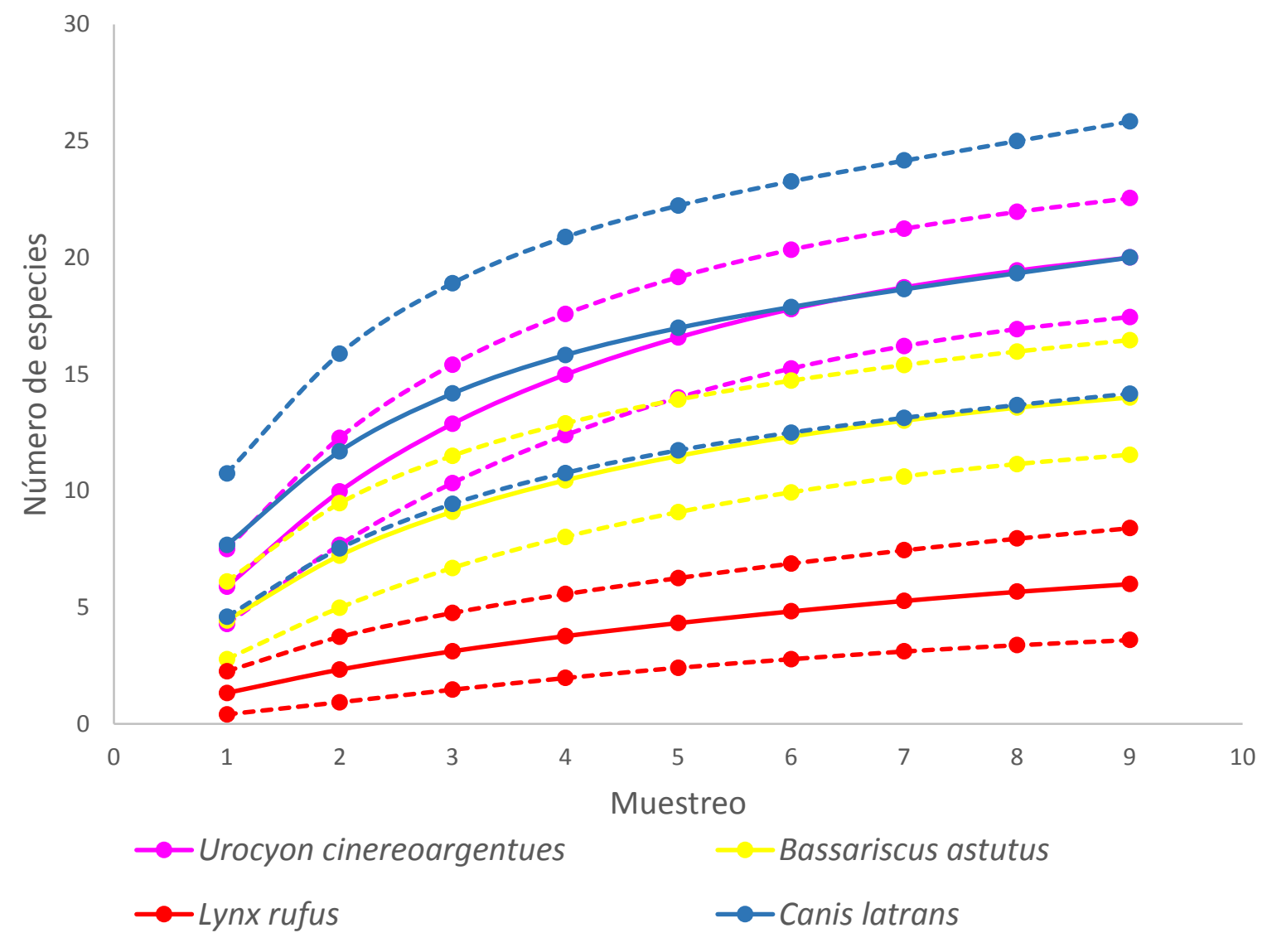

Gráfica 10. Curvas de acumulación de especies consumidas anualmente por el coyote (azul), zorra gris (Fucsia), cacomixtle (amarillo) y lince (rojo) en Otlaltepec, Puebla.

Se utilizaron los estimadores Chao y Jacknife para conocer el éxito del muestreo de los diferentes componentes del nicho alimentario de los cuatro mesodepredadores. Chao 1 calculó dos componentes alimenticios más para el cacomixtle y un componente 
alimenticio más para los otros tres mesodepredadores. Mientras que el estimador Jacknife 1 calculó más de tres componentes alimenticios para cada mesodepredador en el noveno muestreo (Tabla 9).

\begin{tabular}{lccccc}
\hline & Observadas & Chao 1 & $\%$ & Jack 1 & $\%$ \\
\hline Canis latrans & 20 & 21 & 95 & 25 & 80 \\
Urocyon cinereoargenteus & 20 & 21 & 95 & 24 & 83 \\
Bassariscus astutus & 14 & 16 & 88 & 18 & 78 \\
Lynx rufus & 6 & 7 & 86 & 9 & 67 \\
\hline
\end{tabular}

Tabla 9. Valores y porcentajes del análisis de acumulación de especies observadas y esperadas para cada mesodepredador en Otlaltepec, Puebla.

\subsection{Sobreposición de nicho de alimentación}

La zorra gris y el coyote (0.68) presentaron la mayor sobreposición de nicho alimenticio, seguidos por el cacomixtle y la zorra (0.64). En cambio el menor fue entre el cacomixtle y el lince (0.1); seguidos de lince y zorra con el 0.1 (Tabla 10). El análisis realizado con Ecosim 7.0 para la sobreposición de nicho alimenticio anual fue significativo ( $p=0.006$ ), la sobreposición de nicho alimenticio es diferente entre los pares de especies. 


\begin{tabular}{|c|c|c|c|c|}
\hline ANUAL & $\begin{array}{l}\text { Canis } \\
\text { latrans }\end{array}$ & $\begin{array}{c}\text { Urocyon } \\
\text { cinereoargenteus }\end{array}$ & $\begin{array}{c}\text { Bassariscus } \\
\text { astutus }\end{array}$ & $\begin{array}{l}\text { Lynx } \\
\text { rufus }\end{array}$ \\
\hline $\begin{array}{l}\text { Canis } \\
\text { latrans }\end{array}$ & & 0.6848 & 0.5963 & 0.5953 \\
\hline $\begin{array}{l}\text { Urocyon } \\
\text { cinereoargenteus } \\
\text { Bassariscus }\end{array}$ & 385 & & 0.6442 & 0.1512 \\
\hline $\begin{array}{l}\text { astutus } \\
\text { Lynx }\end{array}$ & 278 & 265 & & 0.1109 \\
\hline rufus & 229 & 216 & 109 & \\
\hline
\end{tabular}

Tabla 10. Valores de sobreposición de nicho de alimentación anual (valores por arriba de la diagonal corresponden al índice de sobreposición y los valores por debajo de la diagonal corresponde al número de excretas comparadas), cuantificado mediante la ecuación de Pianka (1973), para las cuatro especies de carnívoros estudiadas en Otlaltepec, Puebla, de diciembre 2015 a enero 2017.

Durante la estación de secas, las especies que tuvieron mayor sobreposición fueron el coyote con la zorra (0.65), seguidos por coyote y el lince (0.59), la zorra y el cacomixtle (0.59) y el coyote y el cacomixtle (0.53); y las de menor sobreposición lince y cacomixtle (0.11) y lince con zorra (0.12). El análisis realizado con Ecosim 7.0 para la sobreposición de nicho alimenticio durante la temporada se secas fue significativo $(p=0.005)$, la sobreposición de nicho alimenticio es diferente entre los pares de especies.

Para la estación de lluvias, las especies que tuvieron mayor sobreposición fueron coyote y zorra (0.7), seguidos por la zorra y el cacomixtle (0.61), coyote y cacomixtle (0.5); y las de menor sobreposición lince con cacomixtle (0.1) y lince con zorra con el 0.2 (Tabla 11). El análisis realizado con Ecosim 7.0 para la sobreposición de nicho alimenticio durante la temporada de lluvias no fue significativo $(p=0.019)$, probablemente se debe a que el número de muestra es pequeño. 


\begin{tabular}{lcccc}
\hline ESTACIONAL & $\begin{array}{c}\text { Canis } \\
\text { latrans }\end{array}$ & $\begin{array}{c}\text { Urocyon } \\
\text { cinereoargenteus }\end{array}$ & $\begin{array}{c}\text { Bassariscus } \\
\text { astutus }\end{array}$ & $\begin{array}{c}\text { Lynx } \\
\text { rufus }\end{array}$ \\
\hline $\begin{array}{l}\text { Canis } \\
\text { latrans }\end{array}$ & & 0.6506 & 0.5265 & 0.5898 \\
$\begin{array}{l}\text { Urocyon } \\
\text { cinereoargenteus } \\
\text { Bassariscus } \\
\text { astutus } \\
\begin{array}{l}\text { Lynx } \\
\text { rufus }\end{array}\end{array}$ & 0.6717 & & 0.5894 & 0.1222 \\
\hline
\end{tabular}

Tabla 11. Valores de sobreposición de nicho de alimentación tanto de secas (triangulo superior) como de lluvias (triángulo inferior), cuantificado mediante el índice de sobreposición de Pianka (1973), para las cuatro especies de carnívoros estudiadas en Otlaltepec, Puebla, de diciembre 2015 a enero 2017.

\section{3 sobreposición espacial anual}

El coyote y el lince fueron las especies que presentaron el más alto índice de sobreposición espacial anual $(\mathrm{C}=0.71)$, seguidos por la zorra gris y el cacomixtle $(\mathrm{C}=$ 0.48); las especies que presentaron el menor índice de sobreposición fueron la zorra gris y el lince $(C=0.12$; Tabla 12$)$.

\begin{tabular}{|c|c|c|c|c|}
\hline ANUAL & $\begin{array}{c}\text { Canis } \\
\text { latrans }\end{array}$ & $\begin{array}{c}\text { Urocyon } \\
\text { cinereoargenteus }\end{array}$ & $\begin{array}{c}\text { Bassariscus } \\
\text { astutus }\end{array}$ & $\begin{array}{l}\text { Lynx } \\
\text { rufus }\end{array}$ \\
\hline Canis & & & & \\
\hline latrans & 1 & 0.3228 & 0.3043 & 0.71 \\
\hline Urocyon & & & & \\
\hline cinereoargenteus & & 1 & 0.483 & 0.1203 \\
\hline Bassariscus & & & & \\
\hline astutus & & & 1 & 0.1438 \\
\hline $\begin{array}{l}\text { Lynx } \\
\text { rufus }\end{array}$ & & & & 1 \\
\hline
\end{tabular}

Tabla 12. Valores de asociación anual que indican el nivel de sobreposición espacial existente, dentro de los transectos delimitados, entre las cuatro especies de mesodepredadores. 


\subsubsection{Sobreposición espacial en las dos temporadas}

Para la temporada seca el coyote y la zorra presentaron el más alto índice de sobreposición espacial $(\mathrm{C}=0.58)$, seguido de la zorra con el cacomixtle $(\mathrm{C}=0.41)$; el coyote y el lince, fueron las especie con el menor índice de sobreposición espacial $(C=0,1)$. En la temporada de lluvias la zorra gris y el cacomixtle presentaron el más alto índice de sobreposición espacial $(\mathrm{C}=0.43)$; mientras que el coyote tuvo el menor índice de sobreposición espacial con la zorra gris, el cacomixtle y el lince $(C=0.1$; Tabla 13).

\begin{tabular}{lcccc}
\hline ESTACIONAL & $\begin{array}{c}\text { Canis } \\
\text { latrans }\end{array}$ & $\begin{array}{c}\text { Urocyon } \\
\text { cinereoargenteus }\end{array}$ & $\begin{array}{c}\text { Bassariscus } \\
\text { astutus }\end{array}$ & $\begin{array}{c}\text { Lynx } \\
\text { rufus }\end{array}$ \\
\hline $\begin{array}{l}\text { Canis } \\
\begin{array}{l}\text { Uatrans } \\
\text { crocyon }\end{array}\end{array}$ & 0.1 & 0.5789 & 0.3949 & 0.0692 \\
$\begin{array}{l}\text { Bassariscus } \\
\text { astutus } \\
\text { Lynx } \\
\text { rufus }\end{array}$ & 0.1 & 0.4375 & 0.4074 & 0.0877 \\
\hline
\end{tabular}

Tabla 13. Valores de asociación tanto de secas (triángulo superior) como de lluvias (triángulo inferior) que indican el nivel de sobreposición espacial existente dentro de los transectos delimitados, entre las cuatro especies de mesodepredadores. 


\section{4 Índice de Marcaje}

\subsubsection{Marcaje de los mesodepredadores en temporada de secas}

El valor promedio del índice de marcaje de las cuatro especies de mesodepredadores, durante la temporada de secas, indican que el lince presentó el más alto índice de marcaje $(I . M=1.8)$, seguido por el coyote $(I . M=1.6)$, la zorra gris $(I . M=1.4)$ y el cacomixtle (I.M=1.2; Gráfica 11).

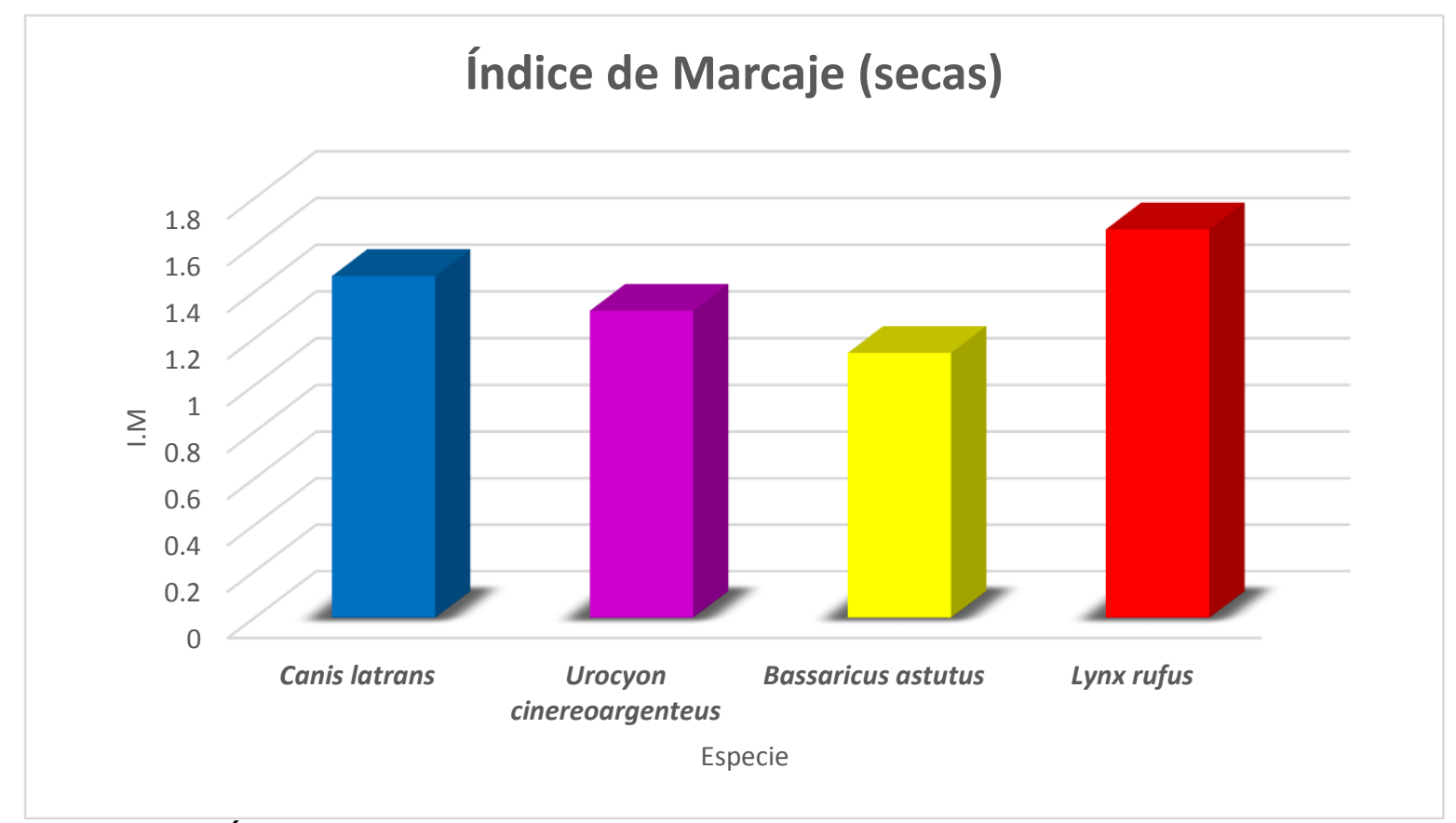

Gráfica 11. Índice de marcaje durante la temporada de secas.

Al comparar los valores obtenidos durante la temporada de secas, no se observaron diferencias significativas entre el índice de marcaje de los 4 mesodepredadores, (Chi cuadrado $=6.242$, g.I. $=3 ; p=0.10$. 


\subsubsection{Marcaje de los mesodepredadores en temporada de lluvias}

El valor promedio del índice de marcaje de las cuatro especies de mesodepredadores, durante la temporada de lluvias, indican que el coyote fue la especie que presentó el más alto índice de marcaje $(I . M=1.5)$, seguido por la zorra gris $(I . M=1.4)$, el lince $(I . M=$ 0.9) y el cacomixtle (I.M=0.2; Gráfica 12).

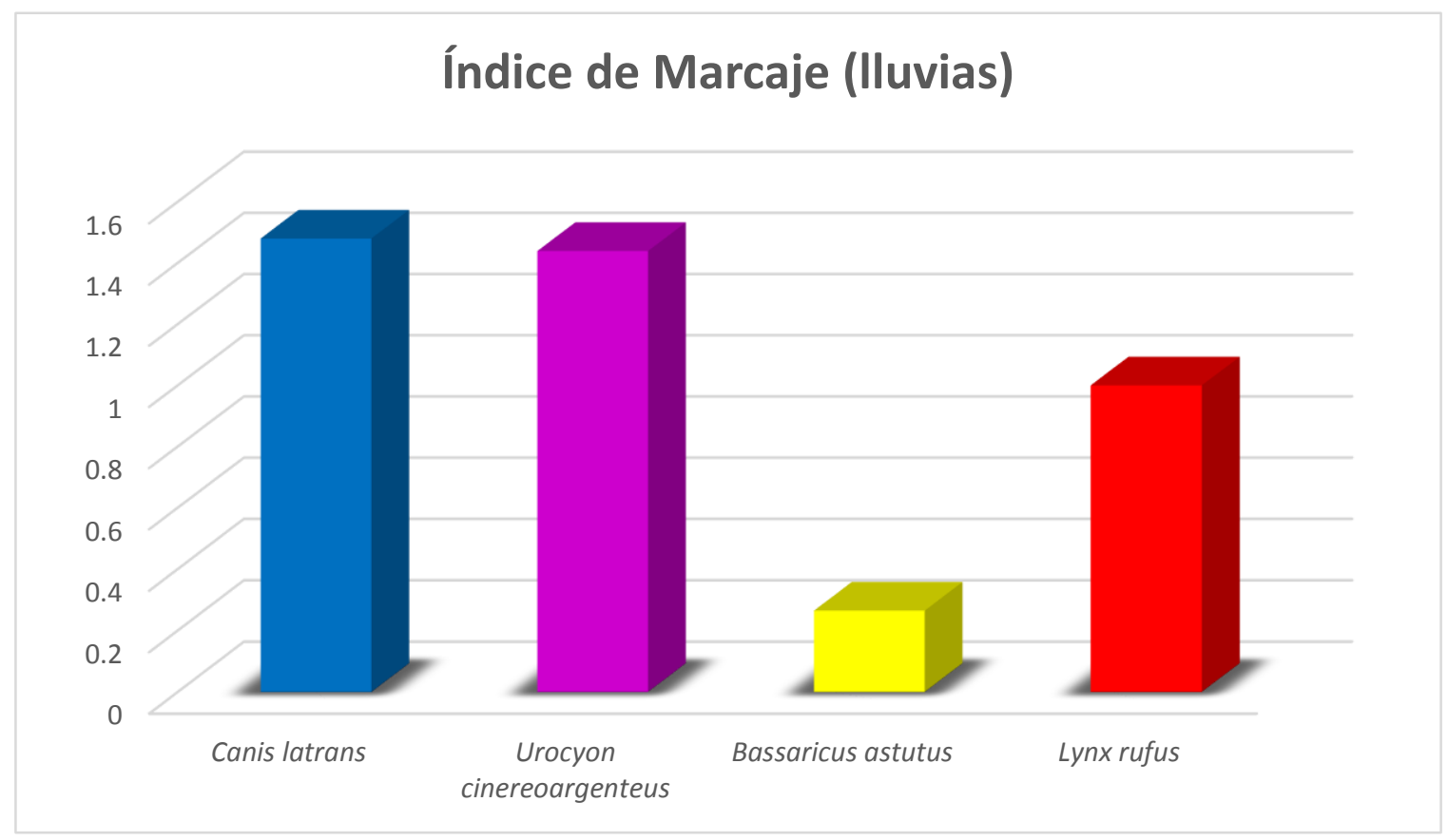

Gráfica 12. Índice de marcaje durante la temporada de lluvias.

Al comparar los valores obtenidos durante la temporada de lluvias, se observaron diferencias significativas entre el índice de marcaje de los 4 mesodepredadores, (Chi cuadrado $=34.998$, g.l. $=3 ; p>0.05)$ 


\subsection{Distribución temporal de los mesodepredadores}

Las cámaras permanecieron activas desde el 12 de diciembre del 2015 hasta el 29 de enero del 2017.

El esfuerzo de muestreo en conjunto para ambas temporadas (lluvia y seca) fue de 2020 trampas noche. Se obtuvieron un total de sesenta y dos registros de mamíferos medianos. El sitio con el mayor número de registro fue "el zorrillo" con 37 , seguido por "la meseta" con 21, 2 en "los mezquites", 1 en "la biznaga” y 1 en "el coco" (Tabla 14).

\begin{tabular}{|l|c|}
\hline \multicolumn{1}{|c|}{ ESPECIE } & $\begin{array}{c}\text { NÜMERO DE } \\
\text { REGISTROS }\end{array}$ \\
\hline Canis latrans & 30 \\
\hline $\begin{array}{l}\text { Urocyon } \\
\text { cinereoargenteus }\end{array}$ & 25 \\
\hline Lynx rufus & 4 \\
\hline Bassariscus astutus & 3 \\
\hline
\end{tabular}

Tabla 14. Número de capturas registradas con cámara trampa para cada especie de mesodepredadores. 
Para analizar el horario en el que los mesodepredadores se encontraban activos, se realizó un histograma circular cuyos ángulos representan las 24 horas del día. En el histograma, cada registro se encuentra simbolizado con un rectángulo. Los registros se agruparon según la hora promedio en la que fueron obtenidos. Los círculos punteados representan el número de registros obtenidos de las diferentes especies de mesodepredadores a lo largo del día (Gráfica 13).

\section{Horarios de actividad}
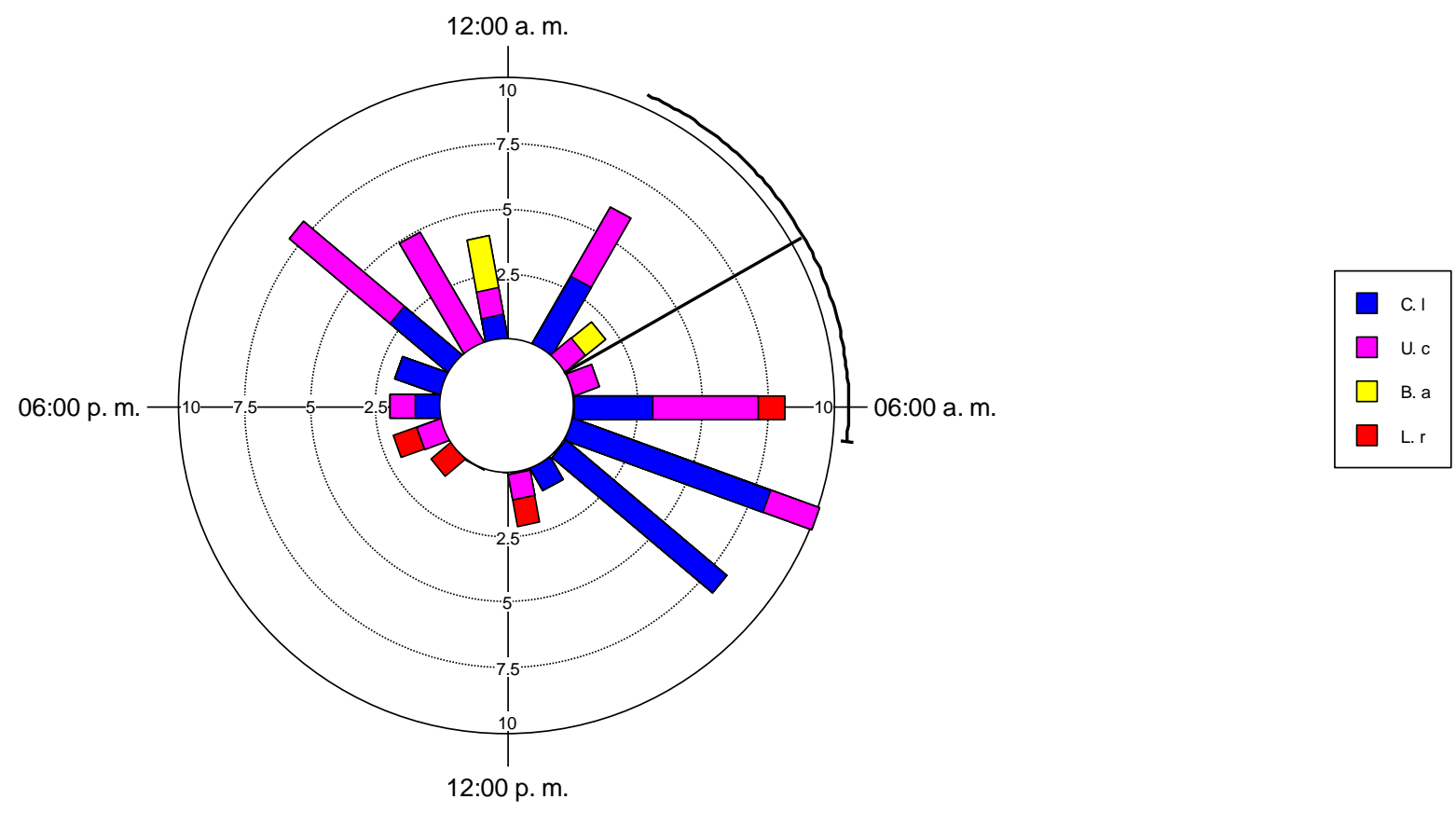

Gráfica 13. Oriana 4.02. Registro de captura por medio de cámaras trampa de los mesodepredadores: coyote (C.I), zorra gris (U.c), cacomixtle (B.a) y lince (L.r). Las cámaras trampa permanecieron activas de diciembre de 2015 a enero del 2017.

\begin{tabular}{|c|c|c|c|c|}
\hline Prueba/Especie & C.I & U. $\boldsymbol{c}$ & B. $\boldsymbol{a}$ & L. $\boldsymbol{r}$ \\
\hline Mean Vector $(\boldsymbol{\mu})$ & $6: 38$ & $0: 42$ & $0: 27$ & $12: 43$ \\
\hline Rayleigh Test $(\boldsymbol{p})$ & $\mathbf{0 . 0 0 1}$ & 0.022 & 0.085 & 0.345 \\
\hline
\end{tabular}

Tabla 15. Vector medio y prueba de Rayleigh de los horarios de actividad de los mesodepredadores. C.I (coyote), U.c (zorra gris), B.a (cacomixtle) y L.r (lince). 


\subsubsection{Actividad de Canis latrans}

De acuerdo con los registros fotográficos el coyote inicia su actividad en el crepúsculo, hasta las primeras horas de la mañana (desde las seis de la tarde hasta las diez de la mañana). El mayor número de registros fotográficos se obtuvieron durante las primeras horas del día ( $\mu$ : 6:38 am; Gráfica 14).
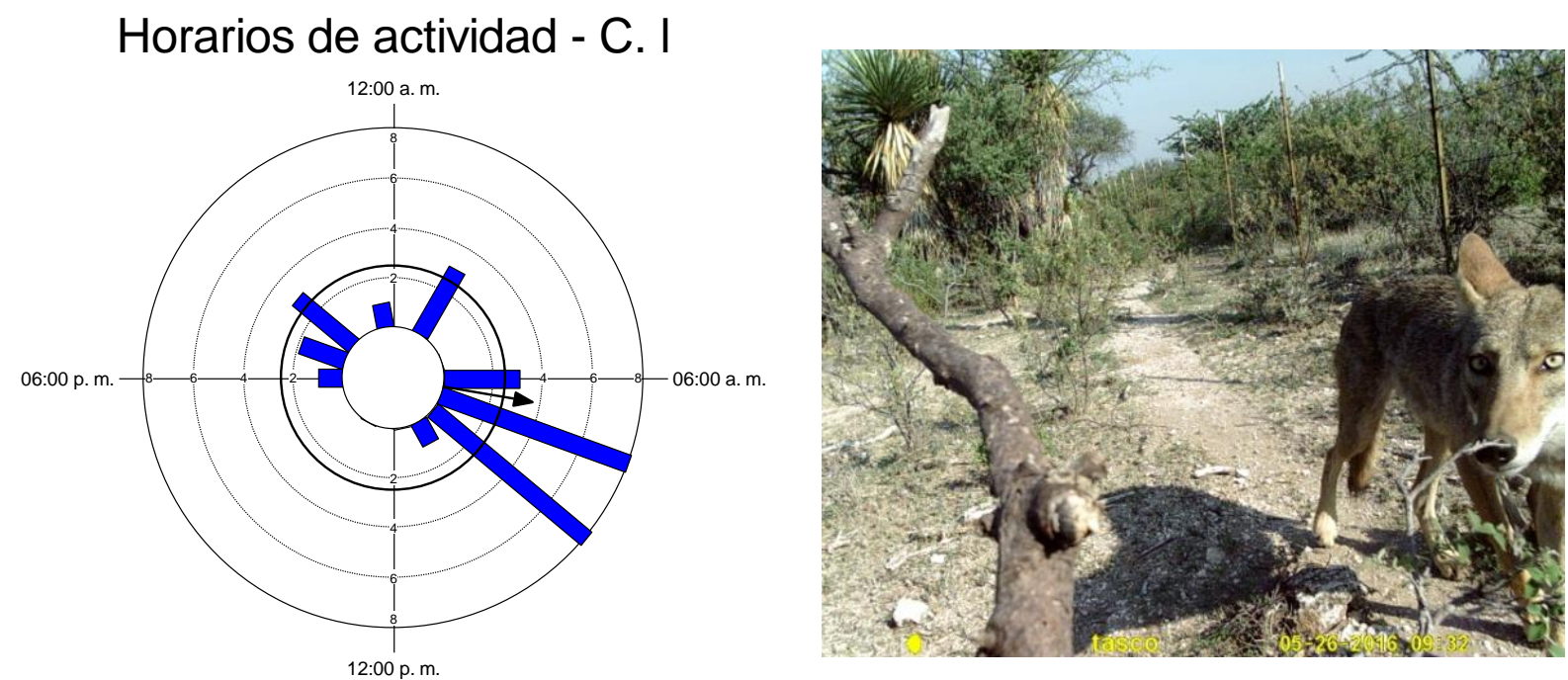

Gráfica 14. Horarios de actividad del coyote (C.I) en un rango de 24 hrs. Los círculos punteados indican el número de capturas obtenidas para esta especie a lo largo del día y las barras azules marcan su acumulación. El vector medio que señala la hora en la que se concentran el mayor número de capturas (6:38 am) es mostrado con una flecha. 


\subsubsection{Actividad de Urocyon cinereoargenteus}

De acuerdo con los registros fotográficos la zorra gris se encontró desde las cinco de la tarde hasta las siete de la mañana, presentando mayor actividad durante la noche.

El mayor número de registros fotográficos se obtuvieron en la media noche $(\mu: 0: 42$ am; Gráfica 15).
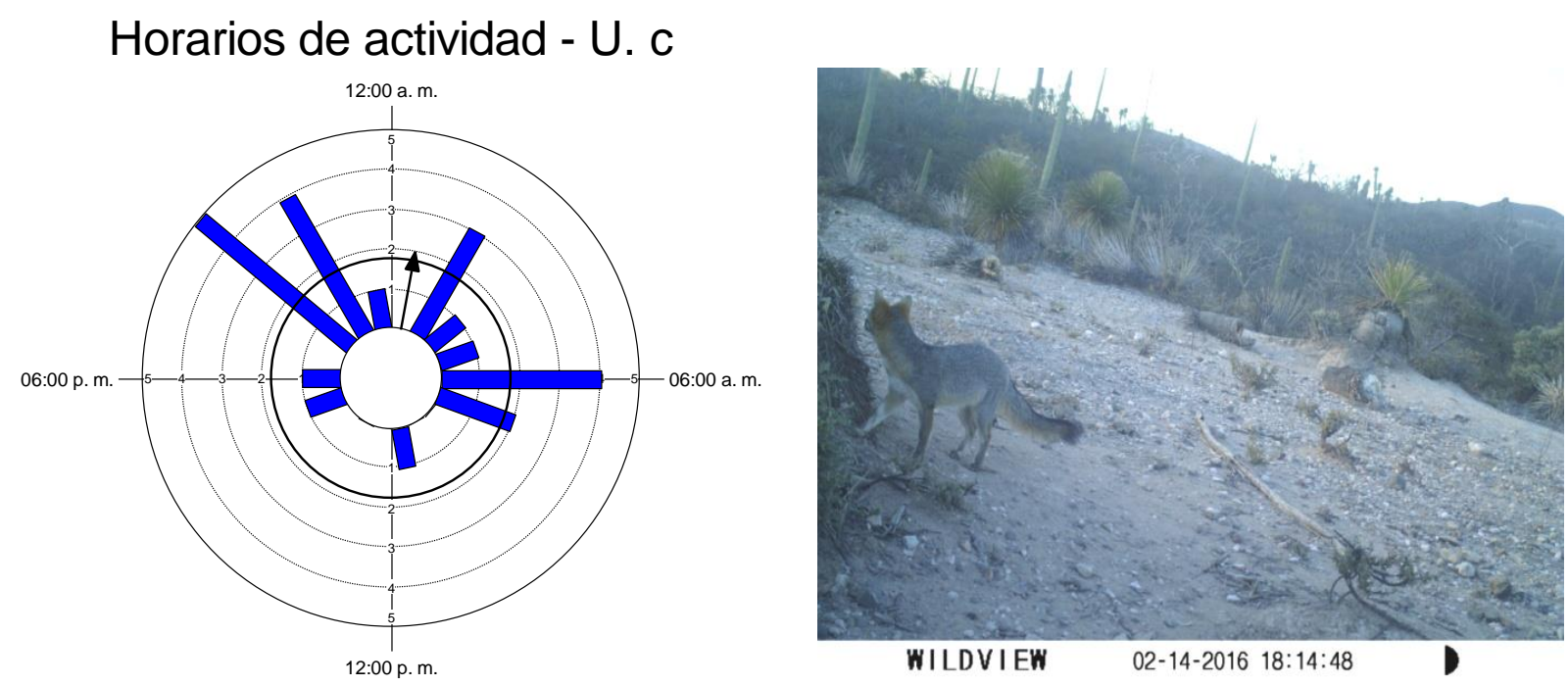

Gráfica 15. Horarios de actividad de la zorra gris (U.C) en un rango de 24 hrs. Los círculos punteados indican el número de capturas obtenidas para esta especie a lo largo del día y las barras azules marcan su acumulación. El vector medio que señala la hora en la que se concentran el mayor número de capturas ( $\mu$ : 0:42 am) es mostrado con una flecha. 


\subsubsection{Actividad de Bassariscus astutus}

De acuerdo con los registros fotográficos el cacomixtle mostró una actividad nocturna. Se encontró desde las once de la noche hasta las tres de la mañana y tuvo mayor actividad durante la medianoche ( $\mu$ : 0:27 am; Gráfica 16).

Horarios de actividad - B. a
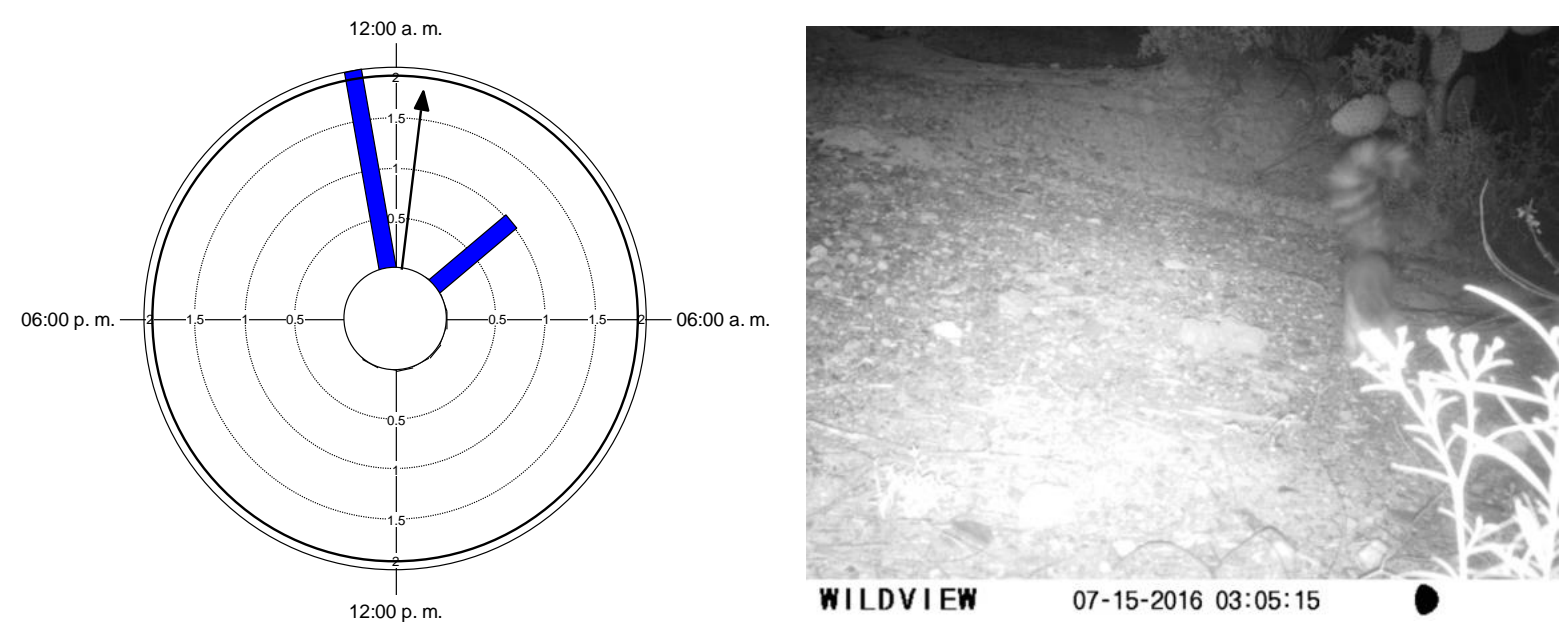

Gráfica 16. Horarios de actividad del cacomixtle (B.a) en un rango de 24 hrs. Los círculos punteados indican el número de capturas obtenidas para esta especie a lo largo del día y las barras azules marcan su acumulación. El vector medio que señala la hora en la que se concentran el mayor número de capturas ( $\mu: 0: 27$ am) es mostrado con una flecha. 


\subsubsection{Actividad de Lynx rufus}

De acuerdo con los registros fotográficos el lince tiene una actividad diurna. Inicia su actividad a las seis de la mañana hasta las cinco de la tarde, presentando la mayor actividad durante pasando el medio día ( $\mu$ : 12:43 pm; Gráfica 17).
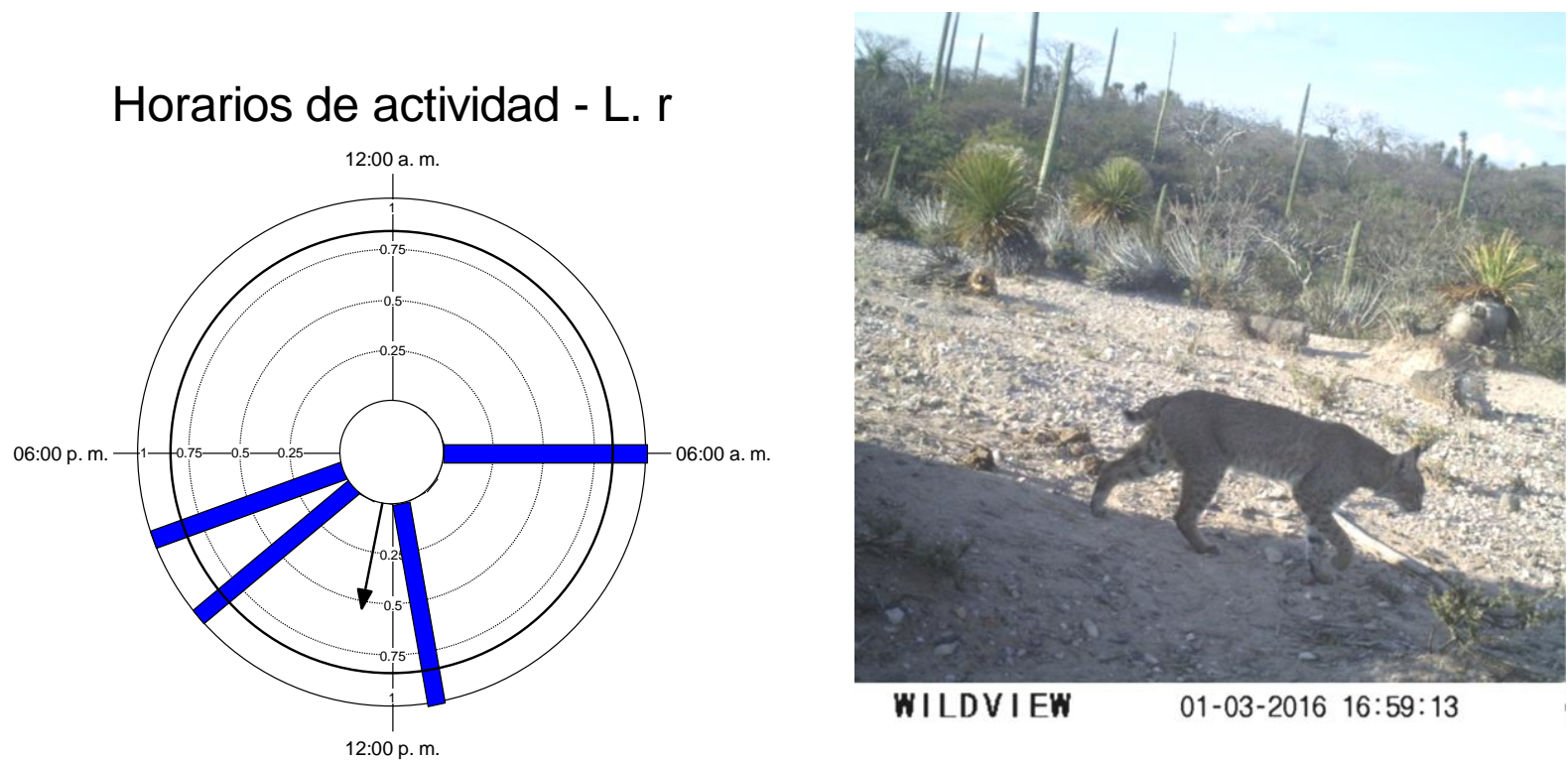

WILDVIEW 01-03-2016 16:59:13

Gráfica 17. Horarios de actividad del lince (L.r) en un rango de 24 hrs. Los círculos punteados indican el número de capturas obtenidas para esta especie a lo largo del día y las barras azules marcan su acumulación. El vector medio que señala la hora en la que se concentran el mayor número de capturas ( $\mu: 12: 43 \mathrm{am})$ es mostrado con una flecha. 


\section{DISCUSIÓN}

La forma en la que los mesodepredadores utilizan las cuatro categorías alimenticias, en función de su peso seco es diferente. Sin embargo, al analizar el consumo de los elementos nutrimentales que se encontraban dentro de las categorías, se puede observar que los mesodepredadores están explotando los mismos elementos aunque en diferentes proporciones. Las tablas indican que al menos las morfoespecies de semillas $1,3,4$ y 12 son importantes para mantener la comunidad de mesodepredadores pues todos explotan al menos algunas de ellas a lo largo del año. De igual manera son los roedores y los lagomorfos las principales fuentes de proteínas para el gremio.

La dieta del coyote fue la más diversa de las especies analizadas. Durante la temporada de secas presentó un mayor consumo de vertebrados, principalmente lagomorfos, seguido por los elementos vegetales, mientras que, para la temporada de lluvias su principal fuente de alimento fueron elementos de origen vegetal, seguido por mamíferos, y en menor proporción aves e insectos. Estos resultados coinciden a lo encontrado por Andelt (1985), para una zona árida de Texas, en donde el coyote alterna su dieta a lo largo del año, pues su principal fuente de alimento durante la temporada de invierno son los mamíferos y durante el verano consume con mayor frecuencia elementos vegetales. En el estudio realizado por Guerrero et al. (2002) para cuatro especies de carnívoros en el bosque tropical caducifolio de Jalisco, los autores encontraron que los mamíferos y la materia vegetal son más frecuentes durante la estación húmeda que en la seca. 
El coyote es considerado un depredador oportunista y generalista, pues su dieta responde a la disponibilidad de alimento que se encuentre presente durante la temporada en la zona (Bekoff, 1977). En el área de este estudio su capacidad adaptativa se vio reflejada al presentar la mayor amplitud de nicho de los carnívoros estudiados durante ambas temporadas indicando un espectro alimenticio más amplio.

A diferencia del coyote, la zorra gris tuvo un comportamiento más especializado, tanto en la temporada seca como en la de lluvia, de acuerdo con los resultados del peso seco y la frecuencia de ocurrencia, los componentes de origen vegetal fueron los dominantes en su dieta.

Villalobos et al. (2014), en un estudio efectuado para la zorra gris en la selva baja caducifolia en Oaxaca, registraron que durante la temporada de secas las semillas predominaron en la dieta de la zorra gris, mientras que las aves y los ortópteros se encontraron en menor proporción. En contraste en la temporada de lluvia, hallaron que los ortópteros y las aves fueron los dominantes a diferencia de lo encontrado por nosotros en la zona de Otlaltepec, en donde los elementos de origen vegetal fueron los dominantes en la dieta de la zorra, y en menor proporción aves e insectos.

Dentro de los vertebrados la zorra tuvo preferencia por los roedores, estos resultados concuerdan a lo encontrado para esta misma especie por Guerrero et al. (2002) en el bosque tropical de Jalisco. Sin embargo, en nuestro estudio el consumo de insectos en ambas temporadas no fue frecuente en la dieta de la zorra. 
Al igual que el coyote, la zorra es muy adaptable ya que explotó más elementos de origen vegetal; dentro de esta categoría consumió nueve de las doce morfoespecies registradas durante el estudio, sin embargo, el consumo de las morfoespecies cambió entre las dos temporadas, así como también cambió la amplitud de nicho alimenticio, que fue mayor durante la temporada seca. Villalobos et al. (2014) mencionan que si bien la zorra incluye frecuentemente frutos dentro de su dieta (esto relacionado a la fenología y disponibilidad del recurso) puede considerarse como una especie "generalista y oportunista" dentro del nicho trófico que explota pues "cambia los componentes pero no la naturaleza de su dieta".

Por otra parte, el cacomixtle tuvo una preferencia por los elementos de origen vegetal durante ambas temporadas, aunque en la temporada de lluvias tuvo un aumento dentro de la categoría de invertebrados donde mostró un mayor consumo de coleópteros y ortópteros. Coincidiendo con lo encontrado por nosotros en Otlaltepec, Nava et al. (1999) en el matorral xerófilo de Hidalgo reportan la preferencia de esta especie por frutos, especialmente los de cactáceas. Estos autores lo consideran como un depredador oportunista, pues aprovecha recursos a los que tiene fácil acceso y evita aquellos que requieren mayor cantidad de tiempo y esfuerzo para su búsqueda y manejo. Los mismos autores también encontraron que el consumo de animales aumenta durante la época de reproducción y gestación, esto es durante la temporada de secas. Similar a esto, en Otlaltepec, el cacomixtle tuvo un mayor porcentaje de consumo de vertebrados en la temporada de secas, que en la de lluvias. 
El lince tuvo un comportamiento alimenticio con preferencia al consumo de vertebrados, principalmente de lagomorfos. Coincidiendo a lo encontrado por nosotros en Otlaltepec, Martínez et al. (2014) en el Parque Nacional Izta-Popo, registraron que los lagomorfos fueron la principal fuente de alimento para el lince. De igual manera Delibes et al. (1997) para una zona árida de Baja California, reportan que el lince se alimenta mayormente de lagomorfos, seguidos de roedores, reptiles y aves. En donde no observaron ninguna variación estacional.

Contrario a esto Larson et al. (2015), encontraron que dentro de los fragmentos de hábitat naturales del paisaje urbano de los condados de San Diego y Orange County, California, el lince tiene preferencia por los roedores y en menor cantidad por los lagomorfos.

McKinney y Smith (2007) para zonas áridas en Arizona reportan que las principales presas para el lince y el coyote fueron los lagomorfos y los roedores, pero el lince consumió más roedores que el coyote independientemente de la estacionalidad y los coyotes consumieron más lagomorfos, frutos/semillas y presas de mayor tamaño (venados), dependiendo de su abundancia durante las diferentes temporadas. Por lo que el coyote presento un mayor consumo de presas grandes y el lince se fue por las de menor tamaño.

Por lo anterior, el lince expone una dieta más restringida, consumiendo las especies de vertebrados que se encuetran presentes (no se ha reportado que se alimente de vegetales o de insectos). 
Respecto al índice de sobreposición alimenticio anual, el coyote y la zorra gris presentan un alto índice de sobreposición debido a que ambas especies utilizan los mismos elementos nutrimentales, dentro de las categorías, sin embargo, la proporción del consumo dentro de estas categorías es diferente para ambas especies durante la temporada de secas y de lluvias.

La zorra y el cacomixtle, también tuvieron un alto índice de sobreposición debido a que estas especies tienen preferencia por elementos vegetales durante ambas temporadas. Esto puede deberse a la adaptabilidad que las especies presentan en su dieta, y a que probablemente el recurso vegetal domine dentro de la zona.

Durante la temporada seca el coyote y el lince también presentaron un alto nivel de sobreposición de nicho, debido a que en esta temporada el coyote consumió más elementos de origen animal y a esto se le agrega que el lince mantuvo una dieta basada en lagomorfos. Es probable que el lince consuma más lagomorfos que roedores porque son más abundantes dentro de la zona (Armella comp. pers; Ortíz 2012).

Martínez et al. (2014) encontraron en el parque nacional Izta-Popo el lince y el coyote se alimentaron principalmente de lagomorfos y roedores, y presentaron un índice de sobreposición alimenticia de 0.94 (El índice tiene un máximo de 1 cuando la sobreposición entre dos especies es total). Contrario a esto el lince y el coyote tuvieron un índice de sobreposición de 0.59 pues en Otlaltepec el coyote actuó de forma generalista y consumió tanto vertebrados como elementos de origen vegetal. 
Nuestro análisis mostró que el alto grado de sobreposición entre la zorra gris, el cacomixtle y el coyote, con base en los datos anuales, se debe a que estas especies tienen una fuerte afinidad por el consumo de elementos de origen vegetal. En cambio como el lince basa su dieta en elementos de origen animal, su consumo no se sobrepone con la zorra y el cacomixtle, como si lo hace con el coyote durante la temporada seca pues esta se encuentra consumiendo los elementos con mayor abundancia.

En la temporada de secas el marcaje de los mesodepredadores fue bajo. Para la temporada de lluvias, el coyote y la zorra gris también tuvieron un índice de marcaje bajo, pero el del cacomixtle y el lince fue nulo. Al respecto Toríz (2014), dentro de la misma zona de estudio, no encontró diferencias en el marcaje tanto entre las especies de mesodepredadores, como entre las temporadas. También reporta que los caminos y las veredas fueron los lugares donde se encontraron excretas con los mayores índices de marcaje aunque con frecuencias bajas. Probablemente no hay diferencias en el marcaje durante secas entre los mesodepredadores porque al ser más escasos los recursos durante esa temporada todas las especies marquen su territorio, compitiendo por los espacios en donde encuentren más recursos. Durante la temporada de secas se da el período de reproductivo del coyote, cacomixtle, lince y la zorra girs, por lo que es probable que el marcaje sea más evidente por la búsqueda de pareja. 
En cambio, la diferencia en el marcaje durante la temporada de lluvias, puede deberse a que en esta temporada exista una mayor disponibilidad de recursos, por lo que el marcaje no sea necesario. Pero el coyote quien ha fungido como la especie dominante dentro de la zona de estudio, continúe ejerciendo esa dominancia y marque en ambas temporadas. Tanto el coyote como la zorra gris son cánidos y el marcaje es una de las características de esta familia. Por otro lado, el cacomixtle se encuentra utilizando los recorridos con poca frecuencia, pues normalmente ésta especie se localiza en zonas más cercanas a los cuerpos de agua. Barja y List (2006), en un estudio realizado en la Ciudad de México, analizaron el marcaje del cacomixtle durante la época no reproductiva y encontraron que esta especie deposita sus excretas en letrinas, y éstas se encuentran sobre objetos por arriba del nivel del suelo. También reportan que las letrinas se encontraron en zonas discretas sobre sustratos conspicuos, pero las excretas que depositaban en lugares conspicuos, se encontraban de forma discreta.

Por lo tanto el marcaje resulta ser más útil entre individuos de la misma especie que entre el gremio, pues cada especie se encuentra marcando de distinta manera en diferentes sitios.

Los coyotes fueron registrados por las cámaras trampa tanto cerca como lejos de las zonas urbanizadas, indicando la adaptabilidad de esta especie dentro de la zona. A pesar de que la mayoría de los registros fueron diurnos, también fue registrado durante la noche. Todo lo anterior se encuentra asociado a su ámbito hogareño y a su mayor amplitud de nicho alimenticio. 
Con respecto a las horas de actividad del coyote, Gipson y Sealander (1972) mencionan que es más activo durante el día, en especial durante las primeras horas de la mañana y en las horas cercanas al ocaso durante los periodos crepusculares.

Armenta et al. (2018) reportan que en el Cañón de las Barajitas, Sonora, el coyote fue más activo durante todo el día, pero tanto esta especie como la zorra gris preferían horarios más nocturnos. También encontraron que la zorra gris presentó una mayor frecuencia de ocurrencia dentro de las zonas con mayor cobertura vegetal.

Por otro lado la zorra gris y el cacomixtle tuvieron mayor actividad durante la media noche, sobreponiéndose en el horario, sin embargo la zorra también se encontró activo en diferentes horas durante el día. Farías et al. (2012) en el chaparral y matorral costero de salvia en el sur de California, encontraron mediante el uso de cámaras trampa que la zorra gris tiene una tasa de actividad crepuscular y nocturna, prefiere el matorral que el bosque y evita las áreas suburbanas. También mencionan que el coyote y el lince pueden estar influenciando a la población de las zorras debido a que éstas parecen estar evadiendo las horas y el hábitat en donde el riesgo de depredación es alto. Contrario a las especies anteriores el lince tuvo mayor actividad durante el día, y fue capturado en los sitios más alejados al poblado (el zorrillo y la meseta) lo que puede estar asociado por la preferencia por los las zonas con menor perturbación.

En un estudio en el Estado de Oaxaca, Marín et al. (2015) reportan que el tamaño promedio del ámbito hogareño de los coyotes fue de $3.45 \mathrm{~km}$. También mencionan que es mayor durante la temporada de secas, que en la de lluvias. Por lo tanto, para 
nuestra zona de estudio, el coyote es capaz de visitar los seis recorridos en un solo día, y al no verse restringido por interferencia con otra especie, ni por la perturbación de las zonas más cercanas al poblado, tiene un mayor rango para la búsqueda y explotación de recursos.

Durante la temporada de secas el coyote tuvo mayor índice de sobreposición espacial con la zorra gris probablemente debido a que, a pesar de que no se hicieron mediciones formales, se pudo observar una menor presencia de vertebrados y mayor diversidad de elementos vegetales, ya que en esta época la disponibilidad de elementos vegetales es menor (C. Amador Com. Pers.) y el coyote tenga que moverse a distancias más largas en busca de alimento, llegando a los sitios en lo que la zorra generalmente se encuentra. Lo mismo puede estar ocurriendo con la zorra gris y el cacomixtle pues el elemento vegetal es la base de su alimentación y al ser escaso durante la temporada de secas (C. Amador, Com. Pers), ambas especies se desplacen a sitios similares en donde el recurso alimenticio se encuentre presente.

Mientras que el lince con la zorra gris tuvieron el menor índice de sobreposición espacial, probablemente debido a que están explotando diferentes elementos nutrimentales y estos se hallen en diferentes sitios. Para la temporada de lluvias la zorra gris y el cacomixtle también presentaron el mayor índice de sobreposición espacial, mientras que el coyote tuvo el menor índice de sobreposición con respecto a los otros mesodepredadores.

Es claro que en este sistema de uso del recurso puede apreciarse la separación de los nichos alimenticios ya que si bien muchos de los elementos nutrimentales están 
presentes en la dieta de los mesodepredadores estudiados, la proporción que cada mesodepredador consume, dentro de las cuatro categorías empleadas para este trabajo, es diferente.

Chamberlain y Leopold (2005) para un estudio sobre la sobreposición en el uso del espacio por el coyote, lince y zorra gris en el sudeste de Estados Unidos reportan que el ámbito hogareño de estas tres especies se sobrepone. El coyote y el lince coexisten compartiendo "áreas núcleo" en un $75 \%$. No obstante el "área núcleo" de la zorra gris se encuentra alejada del lince y el coyote durante todo el año.

La diferenciación de los nichos resulta ser la base de la coexistencia entre las especies, y esta diferenciación puede estar dada a partir de la explotación diferencial de los recursos disponibles. De esta manera las especies evitan la interferencia y posible competencia con otras especies.

El modelo de Lotka-Volterra (Volterra, 1926; Lotka, 1932) como el principio de exclusión competitiva implican que cualquier grado de diferenciación de los nichos permitirá la coexistencia estable de los competidores (Begon et al. 1997). Sin embargo, el nicho ecológico resulta un concepto difícil de medir ya que no es posible definir con exactitud cuál es el grado mínimo de diferenciación que deben existir entre las especies para que estas coexistan o una termine desplazando a la otra. Es por ello que los modelos matemáticos que se basan en la competencia, resultan hasta ahora un buen método para poder medir tanto la amplitud como la sobreposición de nicho de los diferentes organismos interactuantes pues si bien en un estudio de campo es difícil contemplar todas las condiciones que permiten que una especie se encuentre 
ocupando un espacio, es posible medir y relacionar aquellos factores principales que puedan dar una explicación de lo que ocurre dentro de la comunidad.

\section{CONCLUSIÓN}

Las actividades humanas dentro del área de estudio parecen estar afectando de diferentes maneras a los mesodepredadores. Mientras que el lince se restringe a zonas con menor perturbación, al coyote el asentamiento humano aparentemente lo beneficia, pues dentro de su consumo se encontraron restos de aves de corral.

El coyote parece ser la especie dominante dentro del gremio, pues tiene la mayor amplitud de nicho alimenticio fue localizado dentro de todos los transectos, con el mayor número de capturas con las cámaras trampa y su rango de actividad durante el día fue más amplio, además de ser ésta la especie que usa mayormente sus excretas como indicativos de su presencia. Seguido en orden jerárquico por el lince, la zorra y el cacomixtle.

La estructura ecológica funcional del gremio de mesodepredadores en el matorral xerófilo de Otlaltepec, Puebla está dada en función al reparto de la disponibilidad de recursos presentes en la zona a lo largo del año. Existe una diferenciación distinguible en el uso de los recursos alimenticios, espacio y temporales entre las especies integrantes del gremio, esto puede interpretarse como un efecto de la competencia interespecífica y el desplazamiento de nicho. Si bien el índice de sobreposición alimenticio es alto por el consumo de materia vegetal, los dos patrones alimenticios 
encontrados muestran que la competencia interespecífica es menor que la intraespecífica, permitiendo la coexistencia entre las especies.

En una comunidad como Otlaltepec, la disposición de semillas resulta altamente relevante para las especies de carnívoros como recursos alternativos y es en la selección de semillas y otros productos vegetales que se hace más evidente la diferenciación de espacios alimenticios. 


\section{LITERATURA CITADA}

Andelt, W. F. 1985. Behavioral ecology of coyotes in South Texas. Wildlife Monographs. 94: 3-45.

Aranda, M. 2000. Huellas y otros rastros de los mamíferos grandes y medianos de México. CONABIO. Instituto de Ecología, A.C. México. 211 pp.

Arias, A. A., M. T. Valverde y J. Reyes. 2000. Las plantas de la región de Zapotitlán Salinas, Puebla. Instituto Nacional de Ecología Red para el Desarrollo Sostenible, A.C. Universidad Nacional Autónoma de México. México. 80 pp.

Armenta, L., J. P. Gallo., A. Macías., M. Montiel y L. Villarruel. 2018. Ecological niche and occupation by gray fox (Urocyon cinereoargenteus) at Las Barajitas Canyon, Sonora. Therya 9: 53-60.

Arriaga, L., J. M., Espinoza, C. Aguilar, E., Martínez, L. y Gómez, E. (coordinadores). 2000. Regiones terrestres prioritarias de México. Comisión Nacional para el Conocimiento y uso de la Biodiversidad. México. (Disponible en línea:http://www.conabio.gob.mx/conocimiento/regionalizacion/doctos/terrestres.html; última consulta: 22/05/2017.

Barja, I. G. Silván y J. Illera. 2008. Relationships between sexual and stress hormone levels in feces and marking behavior in a wild population of iberian wolves (Canis lupus signatus). Journal Chemical Ecology 34: 697-701. 
Barja, I. y R. List. 2006. Faecal marking behavior in ringtails (Bassariscus astutus) during the non-breeding period: spatial characteristics of latrines and single faeces. Chemoecology. 16: 219-222.

Begon, M., J. Harper y C. Townsend. 1997. Ecología: individuos, poblaciones y comunidades. Tercera edición. Omega. España. 1148 pp.

Bekoff, M. 1977. Canis latrans. Mammalian species. 79: 1-9.

Berger, K.M., Gese, E.M. y Berger, J. (2008). Indirect effects and traditional trophic cascades: a test involving wolves, coyotes, and pronghorn. Ecology, 89: 818828.

Bitetti, M. 2008. Depredadores tope y cascadas tróficas en ambientes terrestres. Ciencia Hoy. 18: 32-41.

Buskirk, S. W. 1999. Mesocarnivores of Yellowstone. 165 - 187 pp. En Clark, T., Curlee, P., Minta, S. y P. Karelva. Carnívores in ecosystems: the Yellowstone experience. Yale University Press. New Haven. USA.

Castellanos, G. 2006. Sobre el ámbito hogareño y los hábitos alimentarios de un carnívoro en un ambiente suburbano. El Cacomixtle (Bassariscus astutus) en la reserva ecológica "El Pedregal de San Ángel". Ciudad Universitaria. México, D.F. Tesis para obtener el título de bióloga. Facultad de Ciencias. UNAM. México. D.F. 
Chamberlain, M.J. y B.D. Leopold. 2005. Overlap in space use among bobcats (Lynx rufus), coyotes (Canis latrans) and gray foxes (Urocyon cinereoargenteus). American Midland Naturalist 153:171-179.

Chame, M. 2003. Terrestrial Mammal Feces: a Morphometric Summary and Description. Memórias do Instituto Oswaldo Cruz 98: 71-94.

Cervantes, F. y B, Riveros. 2012. Mamíferos del Municipio de Cosoltepec, Oaxaca, México. Therya 3:311-325.

Cole, L. C. 1949. The measurement of interspecific association. Ecology, $30: 411-424$.

Courchamp, F., M. Langlais y G. Sugihara. 1999. Cats protecting birds: modelling the mesopredator release effect. Journal of Animal Ecology. 68:282-292.

Crooks, K. R., y M. E. Soulé. 1999. Mesopredator release and avifaunal extinctions in a fragmented system. Nature. 400: 563-566.

Delibes, M., M. Blázquez., Rodríguez-Estrella R. y S. Zapata. 1997. Seasonal food habitats of bobcats (Lynx rufus) in tropical Baja California Sur, Mexico. Canadian Journal of Zoology 74: 476-483.

Farías V., T. K. Fuller y R. M. Sauvajot. 2012. Activity and distribution of Gray foxes (Urocyon cinereoargenteus) in southern California. The Southwestern Naturalist. $57: 176-181$. 
Fritzell, E. K. y K. J. Haroldson. 1982. Urocyon cinereoargenteus. Mammalian species. 189: 1-8.

García-Chávez, J., De la Fuente-Palacios, C., Alonso-Pérez, N. y MartínezRomero, E. 1994. Listado y abundancia de mamíferos carnívoros en los alrededores de Zapotitlán Salinas, Puebla. Memorias del Segundo Congreso Nacional de Mastozoología. Jalisco, México. Pág. 37.

Gehrt, S. D y W. R. Clark. 2003. Raccoons, coyotes, and reflections on the mesopredator release hypothesis. Wildlife Society Bulletin. 31: 836-842.

Gese, E. y R. Ruff. 1997. Scent-marking by coyotes, Canis latrans: the influence of social and ecological factors. Animal Behaviour. 54: 1155-1166.

Gipson, P. S. y J. A. Sealander. 1972. Home range and activity of the coyote (Canis latrans frustor) in Arkansas. Proceedings of the annual conference Southeastern Association of Game and Fish commissioners. 26:82-95.

Guerrero, S., H. Mohammad., S. Zalapa., y A. Flores. 2002. Dieta y nicho de alimentación del coyote, zorra gris, mapache y jaguarundi en un bosque tropical caducifolio de la costa sur del estado de Jalisco, México. Acta Zoológica Mexicana ns. 86: 119-137.

Gwinn, N., Palmer, G. y Koprowski, J. 2011. Virginia opossum (Didelphis virginiana virginiana) from Yavapai County, Arizona. Western North American Naturalist. 71: 113-114. 
Hairston, N. G., F. E. Smith y B. Slobodkin. 1960. Community Structure, Population Control, and Competition. The American Naturalist. 94: 421-425.

Hernández, E., R. Reyna-Hurtado., M. Sanvicente y J. F. Moreira-Ramirez. 2015. Fototrampeo de mamíferos terrestres de talla mediana y grande asociados a petenes del noroeste de la península de Yucatán, México.Therya ns. 6: 559-574.

Hutchinson, G. E. 1957. Concluding remarks. Cold Spring Harbor Symposia in Quantitative Biology. 22: 415-427.

Hunter, M.D., y Price, P.W., 1992. Playing chutes and ladders: heterogeneity and the relative roles of bottom-up and top-down forces in natural communities. Ecology. 73: 724-732.

Hwang, Y. T. y S, Larivière. 2001. Mephitis macroura. Mammalian Species. 686: 1-3.

INEGI. 2009. Prontuario de Información Geográfica Municipal de los Estados Unidos Mexicanos. Atexcal, Puebla. (Disponible en línea: http://www.beta.inegi.org.mx/app/areasgeograficas/?ag=21\#; última consulta: 22/05/2017.

Johnson, C. N., J. L. Isaac. y D. O. Fisher. 2006. Rarity of a top predator triggers continent-wide collapse of mammal prey: dingoes and marsupials in Australia. Proceedings of the royal society. 274: 341-346. 
Kasper, C. B., M. L. Da Fontoura-Rodrigues., G. N. Calvacanti., T. Freitas., F. Rodrigues., T, Oliveira y E, Eizirik. 2009. Recent advances in knowledge of Molina's hog-nosed skunk Conepatus chinga and striped hog-nosed skunk $C$. semistriatus in South America. Small Carnivore Conservation. 41: 25-28.

Krebs CJ. 1999. Ecological Methodology. Addison Wesley Longman, Inc., CA., USA. 620 pp.

Lariviére, S. y L. R. Walton. 1997. Lynx rufus. Mammalian Species 563:1-8.

Larson, R. N., D. J. Morin., I. A. Wierzbowska y K. R. Crooks. 2015. Food habits of coyotes, gray foxes, and bobcats in a coastal southern California urban landscape. Western North American Naturalist 75:339-347.

Livingstone, T., Gipson, P., Ballard, W., Sanchez, D. y Krausman, P. 2005. Scat removal: a source of bias in feces-related studies. Wildlife Society Bulletin 33: 172-178.

Lotka, A. J. 1932. The growth of mixed populations: two species competing for a common food supply. Journal of the Washington Academy of Sciences 22: 461-469.

Marín, A. I., M, Briones-Salas., R, López-Wilchis y J, Servín. 2015. Ámbito hogareño del coyote (Canis latrans) en un bosque templado de la sierra Madre de Oaxaca, México. Revista Mexicana de Biodiversidad 86:440-447.

Martínez, J. A., G. D. Mendoza., F. X. Plata., O. C. Rosas., L. A. Tarango y L. C. Bender. 2014. Use of prey by sympatric bobcat (Lynx rufus) and coyote (Canis 
latrans) in the Izta-Popo nacional park, Mexico. The Southwestern Naturalist 59: 167172.

Mckinney, T., y T. W. Smith. 2007. Diets of sympatric bobcats and coyotes during years of varying rainfall in central Arizona. Western North American. Naturalist: 67:8-15.

Naranjo, E. J., J. C. López-Acosta y R. Dirzo. 2010. La cacería en México. Biodiversitas. 91:6-10.

Nava, V., J. D. Tejero y C. Chávez. 1999. Hábitos alimentarios del cacomixtle Bassariscus astutus (Carnivora: Procyonidae) en un matorral xerófilo de Hidalgo, México. Anales del Instituto de Biología. Serie zoología.70:51-63.

Ortíz, R. L. 2012. Reporte seminario de investigación II "Diversidad de roedores en Otlaltepec, Puebla". (Sin datos de publicación). Universidad Autónoma Metropolitana. $20 \mathrm{pp}$.

Prugh, L., J, Chantal. W, Clinton., T, William., J, William., J, Ripple y S, Brashares 2009. The rise of the mesopredator. Bioscience. 59: 779-791.

Reynolds, J. y Aebischer, N. 1991. Comparison and quantification of carnivore diet by faecal analysis: a critique, with recommendations, based on a study of the fox Vulpes vulpes. Mammal review. 21: 97-122. 
Ritchie E. y C. Johnson. 2009. Predator interactions, mesopredator release and biodiversity conservation. Ecology letters.12: 982-998.

Rzedowski, J. 1988. Vegetación de México. Pimera edición. Limusa. México. $432 \mathrm{Pp}$.

Roemer, G., Matthew, E. \& Blaire, V. 2009. The ecological role of the mammalian mesocarnivore. Bioscience. 59: 165-173.

Smith, E. P. 1982. Niche breath, resource availability, and inference. Ecology 63 (3): 1675-1681.

Smith, T y Robert S. 2007. Ecología. Sexta edición. Pearson. España. 682 Pp.

Soulé, M. E., D. T. Bolger., A. C. Alberts., J. Wright., M, Sorice 1988. Reconstructed dynamics of rapid extinctions of chaparral-requiring birds in urban habitat islands. Conservation Biology.2: 75-92.

Toríz M. A. 2014. Indicadores de Comportamiento en un Gremio de Mesodepredadores Obtenidos por Métodos Indirectos en Santo Tomás Otlaltepec, Puebla (Tesis de maestría). Universidad Autónoma Metropolitana. 90 pp.

Valdespino, C., R. Martínez., L. García. y L. Martínez. 2007. Evaluación de eventos reproductivos y estrés fisiológico en vertebrados silvestres a partir de sus excretas: Evolución de una metodología no invasiva. Acta Zoológica Mexicana n.s. 23:157-180. 
Villalobos, A., A, Buenrostro-Silva y G, Sáchez-de la Vega. 2014. Dieta de la zorra gris Urocyon cinereoargenteus y su contribución a la dispersion de semillas en la costa de Oaxaca, México. Therya 5:355-363.

Volterra, V. 1926. Variations and fluctuations of the numbers of individuals in animal species living together. (Reprinted in 1931. In: R. N. Chapman. Animal Ecology. McGraw Hill, New York).

Wangchuk T. 2004. Predator-prey dynamics: The role of predators in the control of problem species. Journal of Bhutan Studies 10: 68-89.

Wells, M. y M. Bekoff- 1981. An observational study of scent-marking in coyotes, Canis latrans. Animal Behaviour. 29: 332-350. 


\section{Ala \\ Casa abierta al tiempo \\ UNIVERSIDAD AUTÓNOMA METROPOLITANA}

Ciudad de México a 17 de mayo de 2018

C. Aurora Martinez Reyes

Comisariada de Bienes Ejidales

Sto. Tomás Otlaltepec, Mpo. de Atexcal, Puebla

PRESENTE:

Estimada Sra.:

Adjunto a la presente, y de acuerdo a los compromisos que adquirimos ante la asamblea de su comunidad, nos permitimos entregar copia de la Tesis de Maestría titulada ESTRUCTURA ECOLÓGICA DEL GREMIO DE MESODEPREDADORES EN EL MATORRAL XERÓFILO DE OTLALTEPEC PUEBLA, que presenta la Bióloga Alejandra Margarita López Ramos como parte de los requisitos para obtener el grado de Maestria en Biologia que otorga esta casa de estudios.

Aprovecho la oportunidad para agradecerle a Ud., a quienes le precedieron en el cargo y en general a todas las autoridades de la comunidad y a la comunidad misma el apoyo que recibimos para la elaboración de este proyecto.

Este proyecto permite conocer, más a fondo la colección de animales silvestres que habitan en torno a Otlaltepec y, esperamos, sirva para beneficio de la comunidad en su conjunto.

Reiterándole nuestro agradecimiento, le enviamos un cordial saludo

A T E N T A MENTE

"Casa Abierta al Tiempo"

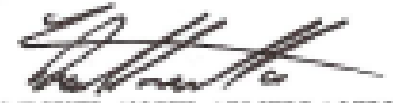

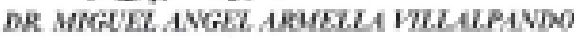

Drector de be resis.

Laboutonio de Fcologla Asinal

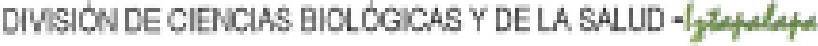

Departamento de Blalagie

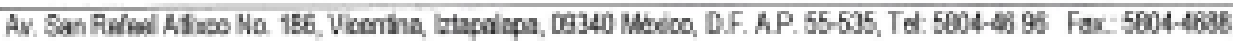

